NISTIR 7473

\title{
An Overview of the Development and Potential Impact of the IEEE 802.16 (WiMAX) Standard
}

\author{
Erik Puskar \\ Standards Coordination and Conformity Group \\ Standards Services Division \\ Technology Services \\ Ted A. Aanstoos \\ Senior Lecturer, Mechanical Engineering \\ Cockrell School of Engineering \\ The University of Texas at Austin
}

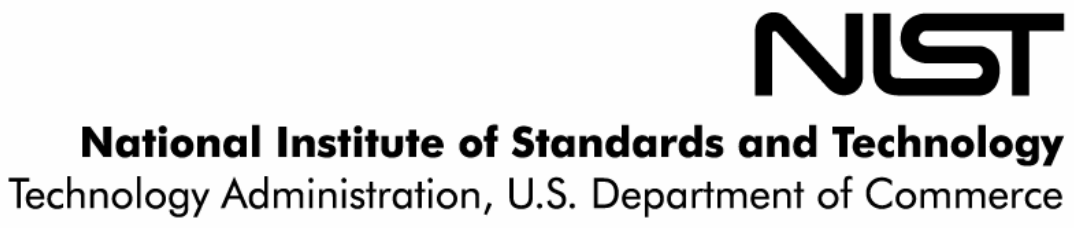



NISTIR 7473

\title{
An Overview of the Development and Potential Impact of the IEEE 802.16 (WiMAX) Standard
}

\author{
Erik Puskar \\ Standards Coordination and Conformity Group \\ Standards Services Division \\ Technology Services \\ Ted A. Aanstoos \\ Senior Lecturer, Mechanical Engineering \\ Cockrell School of Engineering \\ The University of Texas at Austin
}

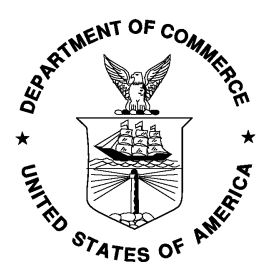

U.S. Department of Commerce Carlos M. Gutierrez, Secretary

National Institute of Standards and Technology James M. Turner, Acting Director 



\section{Table of Contents}

List of Figures and Tables...................................................................... $\mathrm{V}$

List of Acronyms................................................................................... vi

Executive Summary........................................................................... 1

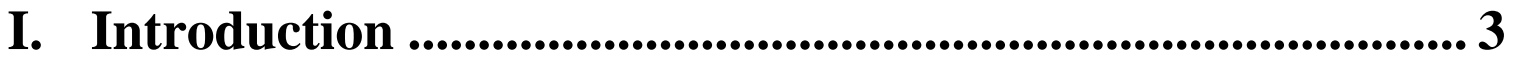

II. Methodology ........................................................................... 4

III. Overview of the Benefits of Standards.................................. 4

IV. WiMAX Technology Overview............................................... 6

V. The IEEE 802.16 Standards Development Effort.............. 7

Overview and History of the 802.16 Working Group ............................................... 7

NIST's role in IEEE 802.16 .............................................................................. 9

NIST's Role as Viewed from Survey Results....................................................... 10

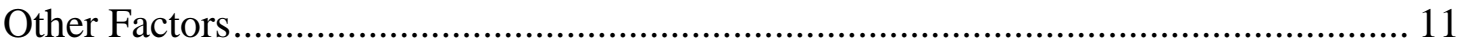

VI. Costs of Developing the 802.16 Standard .......................... 12

VII. Overview and Evolution of the WiMAX Market.......... 13

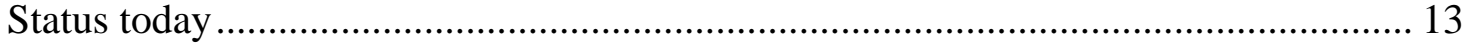

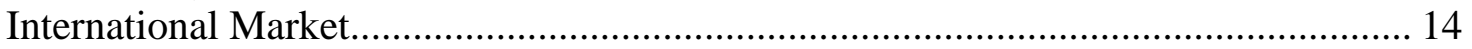

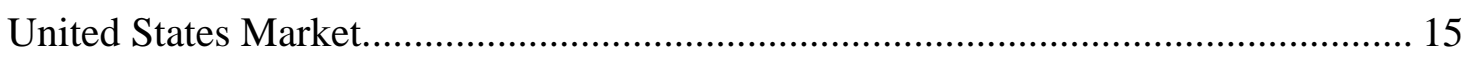

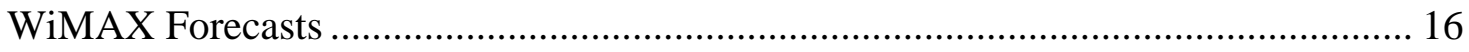

VIII. Benefits ............................................................................ 17

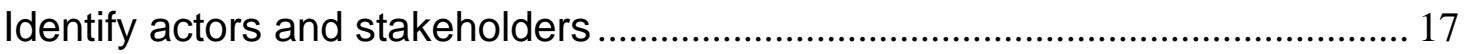

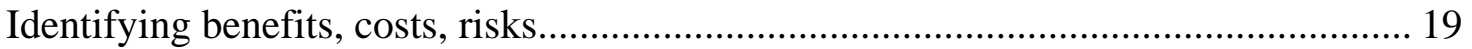

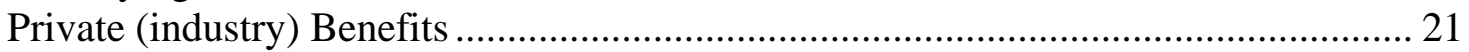

Social/Public Benefits .................................................................................... 23

IX. Digital Divide.............................................................................. 24

X. Projected U.S. municipal wireless market.......................... 26

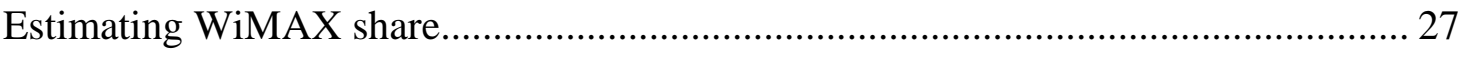

XI. Impact on Innovation and Competitiveness ...................... 29

XII. Other Trends and Indicators of Impact......................... 30

XIII. Challenges................................................................................ 31

XIV. Conclusions............................................................................ 31

Appendix 1. IEEE 802.16 Published Standards and Drafts (as

of 11/2007) ........................................................................................ 34

Appendix 2. Case study: Grand Rapids Michigan ................... 35

End Notes.......................................................................................... 37 


\section{List of Figures and Tables}

Table 1.Total Cost of Participation in the IEEE 802.16 Working Group (thousands) ..... 13

Table 2 Stakeholders Potentially Affected by Benefits/Cost Savings............................ 20

Table 3 Stakeholders Potentially Affected by Increased Costs and Risks....................... 21

Table 4 Actual and projected market for US Municipal Wireless [MuniWireless, 2006] 27

Table 5 Projected WiMAX system expenditures in US municipal wireless BB............. 28

Figure 1 Percentage of WiMAX Deployments by Region (2007) ................................. 15

Figure 2 Accumulated Subscribers by Standard 2006-2012 (source: Maravedis) ........... 16

Figure 3 Annual WiMAX Equipment Market Forecasts ............................................. 17

Figure 4 Estimate of the Acceleration of Benefits Due to the 802.16 Standard............... 22

Figure 5 Survey Results of the Benefits of Adopting the 802.16 Standard ..................... 22 


\section{List of Acronyms}

\begin{tabular}{|c|c|}
\hline ANSI & American National Standards Institute \\
\hline ARPU & Average Revenue Per User \\
\hline BS & Base station \\
\hline CDMA & Code Division Multiple Access \\
\hline DSL & Digital Subscriber Line \\
\hline ETSI & European Telecommunications Standardization Institute \\
\hline EV-DO & Evolution, Data Optimized \\
\hline GSM & Global System for Mobile Communication \\
\hline HSPDA & High-Speed Downlink Packet Access \\
\hline IEEE & Institute of Electrical and Electronics Engineers \\
\hline IMT & International Mobile Telecommunications \\
\hline ICT & Information and Communications Technology \\
\hline ISO & International Organization for Standardization \\
\hline IT & Information Technology \\
\hline ITU & International Telecommunication Union \\
\hline LAN & Local Area Network \\
\hline MAN & Metropolitan Area Network \\
\hline McWiLL & Multi-carrier wireless Internet Local Loop \\
\hline MiMo & Multiple-input, Multiple-output \\
\hline NIST & National Institute of Standards and Technology \\
\hline OFDM & Orthogonal frequency-division multiplexing \\
\hline OFDMA & Orthogonal Frequency-Division Multiple Acces \\
\hline PCI & Peripheral Component Interconnect \\
\hline PCMCIA & Personal Computer Memory Card International Association \\
\hline PDA & Personal Digital Assistant \\
\hline QoS & Quality of Service \\
\hline ROI & Return on investment \\
\hline SiSo & Single-input, Single-output \\
\hline UNCTAD & United Nations Conference on Trade and Development \\
\hline USAID & U.S. Agency for International Development \\
\hline USB & Universal Serial Bus \\
\hline VoIP & Voice over Internet Protocol \\
\hline WAN & Wide Area Network \\
\hline WLAN & Wireless Local Area Network \\
\hline WiBro & Wireless Broadband (Korea) \\
\hline Wi-Fi & Wireless Fidelity (based on IEEE 802.11 standard) \\
\hline WiMAX & Worldwide Interoperability for Microwave Access \\
\hline WWAN & Wireless Wide Area Network \\
\hline
\end{tabular}




\section{Executive Summary}

WiMAX (a term originally devised as an abbreviation for Worldwide Interoperability for Microwave Access), is a revolutionary communications technology based on the IEEE 802.16 standard of the Institute of Electrical and Electronics Engineers (IEEE). This standard makes computer network applications mobile, at broadband speeds, with a new and growing family of internet-connected devices at speeds several times faster than current third-generation (3G) cellular speeds.

This paper discusses the IEEE 802.16 standard for Wireless Metropolitan Area Networks as an example of the high impact of documentary standards developed with active participation by staff of the National Institute of Standards and Technology (NIST). Under the leadership of NIST staff, the 802.16 Working Group was formed and first met in 1999. The plan developed by this group did not follow the traditional telecommunications model of creating one or more national standards and then moving toward an international standards competition. Instead, the plan was to follow the practices established in data communications that had led to the global international standards underlying the Internet. Since then, the 802.16 Working Group has developed several versions of its standard, which is now becoming widely implemented in the United States and globally. Our research show that the Working Group participants found that NIST's role in the development of the standard was extremely useful because it served as a neutral party, helped to bring together diverse interests, and probably accelerated the development of the standard. We estimate the cost of developing this standard over a seven-year period as approximately \$200 million, borne primarily by the private sector. The resulting technology is currently undergoing commercialization; many communications and technology companies are currently in the process of producing or deploying equipment and services based on the standard. WiMAX has the potential to become a disruptive technology with an impact on consumers and both the broadband and wireless industries globally. Market forecasts estimate tens of millions of users within five years.

With regard to benefits, the paper identifies the various stakeholders and likely benefits, reviewing some of the private benefits to industry as a result of participating in the development and adoption of the standard. Market access/creation was the largest single benefit identified, followed by supply chain flexibility and mix-and-match interoperability. Societal benefits of the technology include increased capabilities, product diversity, and reduced prices. This may reduce the "digital divide"; i.e., the gap between those with regular effective access to digital information and technology and those without it. Of course, as with any disruptive and transformative technology, there are risks and challenges associated with WiMAX. With many competing technologies to contend with, the ultimate business decisions, implementation, and customer adoption of WiMAX products and services are still uncertain.

In order to address these topics, the authors surveyed a small number of industry members of the IEEE 802.16 community, conducted a literature review of wireless 
technologies and related market assessments and forecasts, and gathered data from industry and news service reports and articles. This study is a building block in the effort to develop a methodology for conducting evaluations of documentary standards efforts. Based on the background and data compiled in this study, a complete economic analysis effort can be undertaken once WiMAX has been fully commercialized with measurable benefits in the next 3 to 5 years. 


\section{Introduction}

This study is part of an effort by NIST Technology Services to assess the impact of standards on competitiveness and innovation. The goal of this study is to determine the types of impact potentially resulting from the IEEE 802.16 standard, as well as to evaluate the effectiveness of NIST's participation. It also looks to add to the general body of knowledge regarding the impact of documentary standards.

The development and expansion of broadband wireless technologies derives from the fusion of telephones and personal computers, morphing into fully integrated mobile devices and creating many opportunities for networked systems of such devices. WiMAX (a term originally developed as an abbreviation for Worldwide Interoperability for Microwave Access), is a revolutionary communications technology based on the IEEE 802.16 standard. It provides for mobile wireless links, at broadband speeds, with a new and growing family of internet-connected devices. ${ }^{i}$ WiMAX is capable of delivering data to mobile devices at rates several times faster than current third-generation (3G) cellular speeds. It can also be used to deliver broadband service to the home or business as an alternative to cable or digital subscriber lines (DSL). WiMAX is a new technology with the potential to ultimately allow societies to become connected internally as well as globally. What differentiates WiMAX from other broadband wireless options is that it is based on an open standard using a new technology, not an evolution of an existing one, as is the case with competing technologies evolving from Code Division Multiple Access (CDMA) and Global System for Mobile Communications (GSM).

This report summarizes the impact of the IEEE 802.16 standard for Wireless Metropolitan Area Networks. This topic was selected following an activity in which NIST's Technology Services organization canvassed NIST's laboratories for examples of high impact documentary standards with NIST involvement. ${ }^{\text {ii }}$ The IEEE 802.16 standard was selected for study for several reasons. First, the subject matter is very timely since the resulting WiMAX technology is in the midst of being commercialized. Many communications and technology companies are currently producing or deploying technology based on this standard, both in the United States and globally. Secondly, the chair of the 802.16 Working Group is a former NIST staff member. Moreover, WiMAX has the possibility of becoming a disruptive technology with market forecasts estimated in the tens of millions of users within five years.

Due to the scope and timing of the study, coming during the early part of the commercialization phase, a full quantitative impact analysis could not be conducted. Instead, this study offers a qualitative assessment of the different aspects of the scope and nature of impacts, which include market assessments, ecosystem creation, product diversity, new uses for the technology, cost and revenue projections. The report covers the methodology, a brief overview of WiMAX technology, an overview of the benefits of standards, a descriptive overview of the development of the IEEE 802.16 standard, and an estimate of the cost to develop the standard. We also review NIST's role in the 
development of the standard and attempt to determine the significance of that contribution. An overview of the WiMAX market is followed by an identification of stakeholders and the potential benefits to them, as well as a description of private, public, or societal benefits. We attempt to describe the potential gains, both to industry, in terms of increased markets and productivity gains, and to end-users, , in terms of increased functionality and greater variety of devices supporting broadband. Following from social public benefits, the effect of WiMAX on the digital divide is addressed. An analysis of the municipal wireless market includes an estimate of the potential WiMAX share. The role of the standard in promoting or inhibiting innovation will also be discussed. Of course, as a disruptive and transformative technology, there are risks and challenges associated with WiMAX, and these are considered as well.

\section{Methodology}

The topic of this case study was chosen from among 55 projects identified in a canvass of NIST laboratories in 2006 to identify high impact standards with potential for broad adoption. In selecting topics for economic impact assessment, NIST considers the likelihood of substantial market impact in the near future. ${ }^{\text {iii }}$ NIST's contribution to the standardization effort was also a consideration for selection.

Due to the limited availability of benefit data, it is not yet possible to calculate economic impact. This paper will instead identify qualitative, societal (non-economic), and anecdotal benefits in order to paint a picture of the current and expected impact of the IEEE 802.16 standard.

Much of the data for addressing the project goals came from literature reviews of wireless technologies, related market assessments and forecasts, and data-gathering from industry and news service reports and articles. The core of the study is based on a survey of ten firms involved in the development of WiMAX-related products or services; each of these firms had some participation in the IEEE 802.16 Working Group. That survey included questions regarding participation in the working group, views on the effectiveness of NIST's participation, and the impact on company costs and potential revenues

Indications of potential significant economic impact might lead to a follow-up study to quantify realized benefits and near-term, high probability prospective benefits, and to compare these to the costs of developing the standard.

\section{Overview of the Benefits of Standards}

The role of standards in encouraging technological diffusion and/or progress regarding technical change has been demonstrated empirically in previous studies. ${ }^{\text {iv }}$ Standards are therefore perceived with growing importance by industry and governments around the world. Standards exert influence on technical change in a complicated 
manner, but whether and to what extent standards lead to change varies from one case to another. ${ }^{v}$ Potential benefits are reviewed below and will be discussed in the context of wireless broadband throughout this paper.

The widely accepted general benefits of standards include the following:

1. Interoperability or compatibility between different elements in a system or network. Integrated and complete systems can be formulated through an alliance of different suppliers and makes market entry possible, or perhaps simply easier, for small and innovative firms. Interoperability also promotes efficiency and network effects.

2. Provision of a minimum level of quality, which may be defined in terms of functionality, reliability, maintainability or safety of products. This category includes certification of compatibility (i.e., accreditation by independent testing organizations) and presents an aspect of quality to consumers.

3. Reduction of variety, which leads to economies of scale and building a critical mass of new products

4. Provision of information which, as long as it is accessible, will help level the playing field among rivals. This reduces the costs of interaction, which includes transaction, communication and coordination costs.

With regard to cost-effectiveness and productivity, it is known that standards will impact a company's design and technical specifications of a product, its marketing of a product, the production process, and the production facilities, leading to:

- improved efficiency in design, development and material acquisition;

- reduction in resource usage, such as manpower, time, and natural resources;

- $\quad$ enhanced interchangeability, reliability, safety and maintainability. ${ }^{\mathrm{vi}}$

In addition to the above benefits, Hesser, Czaya and Riemer mention the importance of standards on the constitution of the market, which includes market creation, market development, conditioning of market characteristics and increasing turnover. $^{\text {vii }}$

The impact of standards also extends to international trade: studies have shown that standards generally exert positive influence on transaction of goods and services across borders. In the presence of global network externalities, which apply to the broadband wireless industry, the existence of internationally recognized standards serves as a necessary condition for international trade in these products and/or services. In addition, the existence of agreed standards in industries that are global in scope also reduces the cost of entry to foreign markets. According to the study conducted by DIN (2000), 84 percent of companies surveyed use European and international standards as part of their export strategy in opening up new markets. viii

Both pro-competitive and anti-competitive effects of standards can be generated at the same time by a single standardization activity. For example, dominant firms might 
manipulate the outcome of the standardization process; companies with large networks of customers can use economies of scale to impose a market-access barrier on potential entrants because of their low costs, and hence low prices; firms may use a pricing strategy to establish a monopoly position; and strategic alliances of producers can use the formal standards process to publish product specifications that impose considerable costs upon current rivals outside their coalition. With regard to trade, a government can set standards in favor of domestic producers and at the expense of foreign competitors. ${ }^{\text {ix }}$

\section{WiMAX Technology Overview}

"WiMAX" is an informal term for the technology under discussion. It derives from the name of the WiMAX Forum, an organization formed in 2001 in order to certify broadband wireless products in order to guarantee "Worldwide Interoperability for Microwave Access.” That organization has expended significant effort in developing and maintaining laboratory certification programs to certify the compliance of products with the IEEE Std 802.16 “Air Interface for Broadband Wireless Access Systems.”

The first version of the IEEE 802.16 standard (IEEE Std 802.16-2001) addressed only stationary systems, targeting mainly the high-capacity links to business facilities through an outside rooftop antenna. The basic structure was developed around the notion of a radio base station (BS) - not unlike those in cellular telephone systems communicating with remote subscriber stations. Because business might require a range of services, some of them very time-critical, the standard was built to support detailed management and control of Quality of Service (QoS) requirements. The level of QoS sophistication in IEEE 802.16-2001 raised the bar for wireless communications.

Before this work was even finished, however, the Working Group began activities to enhance the standard to support service to consumers without an external antenna. For this purpose, orthogonal frequency-division multiplexing (OFDM) was introduced. By dividing the radio channel into many narrow subchannels, this technology combines the benefits of a large frequency band - for large data capacity - with the advantages of narrow channels that can be more accurately transmitted through complicated environments. This work led to the development of IEEE Std 802.16-2004, in which OFDM allowed for service even without a line of sight from the BS. OFDM is well suited for use with advanced antennas, and the standard incorporated features such as multiple-input, multiple-output (MIMO) antenna systems.

The 802.16 Working Group then turned to its next goal - extending the standard to provide service to fully mobile users. That work, which began in 2002, concluded with the completion of the amendment IEEE 802.16e in 2005. For this activity, attention turned toward a technology included in the earlier standard, but not fully exploited previously: orthogonal frequency-division multiple access (OFDMA). In this sophisticated technology, the entire set of subchannels of spectrum need not be used by a single transmitter at any given time; instead, the set of subchannels can be divided into subgroups that can be used simultaneously by different transmitters. This adds significant 
complexity, but has major advantages, allowing a more efficient use of the spectrum. Since this was a superior technology for mobile broadband, the working group concentrated on developing and refining it while adding mobile-specific features, such as the ability to hand over a connection from one BS to the next as the subscriber moved from one to another. This version of the standard has been dubbed "Mobile WiMAX".

In order to understand WiMAX, it is useful to compare and contrast it with Wi-Fi, a wireless broadband technology based on IEEE Std 802.11. These standards use different underlying technologies and were developed for different application sets. WiFi signals are effective at "hot spot" ranges on the order of tens of meters, while WiMAX offers large municipality coverage while supporting business-class QoS requirements. Wi-Fi operates in unlicensed frequency bands, while WiMAX is generally used in licensed spectrum. Furthermore, Wi-Fi is a mature technology firmly embedded in hundreds of mass-produced products and services, while the ultimate success of WiMAX hinges on business strategy and marketplace economics.

\section{The IEEE 802.16 Standards Development Effort}

\section{Overview and History of the 802.16 Working Group}

The U.S. Government began to deregulate the wireless communications industry in the 1990s. Regarding wireless communications, the United States in 1994 took the position that spectrum would be auctioned to private users, who would then be largely free to decide on its use. Following years of regulated specifications, the U.S. wireless communications industry was slow to develop the traditions of consensus standardization. In the 1990s, Europe's broadly supported GSM standard developed a strong position in the world market for "second-generation" cellular telephones, while the U.S. market remained fractured. The standards wars of "third-generation" cellular were fought by many companies and consortia, and ultimately in the International Telecommunications Union (ITU).

In 1998, NIST began to study fixed broadband wireless access systems providing high-speed network access to businesses, homes, and other stationary sites, generally through rooftop antennas [x]. NIST found little evidence of U.S. or worldwide efforts to standardize such services, although an early program had begun in the European Telecommunications Standards Institute (ETSI). This application seemed ripe for standards [xi,xii], but industry seemed to need a catalyst. NIST assumed that role and called a meeting to discuss the topic in August 1998. With the participation of 45 attendees, a plan was crafted to initiate the standardization process.

The plan developed by this group did not follow the traditional telecommunications model of creating one or more national standards and then moving

toward an international standards competition. Instead, the plan was to follow the 
traditions established in data communications that had led to the successful global standards that underlie the Internet.

Following that model, the NIST-initiated group, after considering possible consortium development, elected to proceed with standardization through the ANSIaccredited IEEE Standards Association (IEEE-SA), the standards-developing arm of the Institute of Electrical and Electronics Engineers (IEEE), a transnational nonprofit technical society of over 350,000 members. ${ }^{\text {xiii }}$ In particular, that group approached the IEEE 802 LAN/MAN (Local/Metropolitan Area Networks) Standards Committee. IEEE 802 is the source of the ubiquitous Ethernet standards that define local area networks that have rapidly turned new technology into readily available commodity equipment. IEEE 802 had also taken the lead in wireless data networking, with an active and successful project in the IEEE 802.11 Wireless LAN standards as well as a more recent effort developing the IEEE 802.15 Wireless Personal Area Network standards. ${ }^{\text {xiv, xv }}$

In two months, the NIST-pioneered effort to create standards for fixed broadband wireless access led to an IEEE 802 Study Group chartered to develop a standardization plan. Four months later, this plan was approved, and the IEEE 802.16 Working Group on Broadband Wireless Access ${ }^{\mathrm{xvi}}$ was created and chartered to develop its first standards project. The project attracted broad global interest, eventually drawing members from 13 countries. The Study Group held bi-monthly week-long sessions and the work moved quickly. The core standard defining the WirelessMAN® air interface was approved as IEEE Standard 802.16 in 2001. ${ }^{\text {xii,xviii }}$ Fifteen additional standards to enhance the applicability of the work and aid deployment of the systems have also been published, with several more under development. ${ }^{\text {xix }}$

Beginning in late 2002, the IEEE 802.16 Working Group undertook to expand the WirelessMAN standard so that it would apply to mobile, as well as fixed, user devices. This project, entitled 802.16e, resulted in a surge of membership. The work concluded with the publication of IEEE 802.16e-2005. The resulting standard became the basis of the Mobile WiMAX certification procedures and led to the commitment of hundreds of companies into the business ecosystem of suppliers of systems, chips, end-user devices and operators. In 2006, IEEE requested that IEEE Standard 802.16 be added to the International Telecommunications Union (ITU-R) “IMT-2000” recommendation for International Mobile Telecommunications. IMT-2000 is a global standard defined by ITU in a set of interdependent ITU Recommendations that include the specifications for the radio interfaces of these advanced wireless communications systems. In October 2007, the ITU Radiocommunication Assembly granted final approval of an update to Recommendation ITU-R M.1457, the core IMT-2000 specification. The update includes a new sixth radio interface, "IMT-2000 OFDMA TDD WMAN", that is based on a normative reference to IEEE Standard 802.16. This is the only radio interface added to IMT-2000 since the five original ones adopted nearly a decade earlier.

As of 2007, interest in the IEEE 802.16 Working Group continues to grow. Membership has risen to 377 individuals, and attendance has been as high as 462 people 
at a week-long session. A complete list of active 802.16 standards and drafts under development is included in Appendix 1.

Our survey respondents cited what they perceived to be long-term benefits from participating in the IEEE 802.16 Working Group. The reasons ranged from helping to influence technology developments to marketplace benefits. Some comments on the benefits of participation are summarized below and include:

- $\quad$ Staying current on the latest technical developments; networking with other vendors

- Would like to ensure that the next generation standards take advantage of the latest technologies that have been field proven.

- Customers who are taking advantage of benefits today using proprietary technologies would like the standard to have these technologies included so they can take advantage of economies of scale

- Influence in the development of standards-based products with large volume potential

- Allows building a single technology solution for fixed and mobile broadband networks

- Interoperable products from multiple vendors. Better price and functionality.

- Possible lower cost solution to existing 3G

- Ability to influence direction of long-term evolution of OFDMA broadband wireless systems (i.e., 802.16m)

\section{NIST's role in IEEE 802.16}

In 1998, NIST began the previously-described activities that led later that year to the initiation of the IEEE 802 Study Group on Broadband Wireless Access. The NIST staff member who had organized the activities, Roger Marks, was named by the IEEE 802 Executive Committee to Chair that Study Group. Four months later, the IEEE 802.16 Working Group on Broadband Wireless Access was formally chartered to develop the IEEE 802.16 standard. At the first official meeting, Marks was the only candidate standing for election as Chair of the Working Group and was elected by the membership. Marks was subsequently re-elected as Chair in 2000, 2002, 2004, and 2006, all the while as a staff member at NIST.

Virtually the entire role of NIST in the 802.16 Working Group was in its support of the Chair. As described in the previous section, it was a catalyst in undertaking this effort and hosted the initial meeting from which a plan to proceed with standards activity was developed. The support provided by NIST played a significant role in the progress of the Working Group. Nearly every other member of the Working Group was an industry employee. The focus of many of these participants was on activities that would further the interest of the employer. In a standards activity, many employers are hesitant to participate in leadership positions because they feel that this requires objectivity that may impair their ability to drive toward company interests. Other employers may simply feel that the time and energy that goes into effective group leadership comes at the expense of 
company goals. NIST's willingness to provide the leadership helped to eliminate much of the potential strife and difficulty of choosing an industry leader, and it allowed the Chair to invest significant time and energy fulfilling the basic tasks, including organizing the work, planning meetings when necessary, identifying and appointing subgroup leaders, publicizing the activity, attracting new participants, negotiating agreements between opponents, serving as technical editor, etc.

To the extent that the majority of the participating companies were US-based, the Chair was generally perceived as neutral. However, a concerted effort was made to globalize the work and draw in participants from around the world. With a worldwide audience, a U.S. Government official might not have been perceived as neutral. Fortunately, NIST has an excellent reputation for technical neutrality, and its staff member was able to cement that reputation in the Working Group.

This activity helped to fulfill NIST’s mission in several ways:

1. By encouraging standardization through the voluntary consensus standards process, the work supports federal goals.

2. By encouraging the development of standards in an open, global, technically based, consensus process, the project ensures that all participants, large and small alike and regardless of nationality, can, if they have the resources, have access to the process so that the resultant outputs are likely to be of high quality.

3. By accelerating standardization, the work moves broadband wireless access closer to widespread deployment. This expands opportunities for equipment vendors and service providers.

4. By leading to wider deployment, standardization will offer more broadband access alternatives to a wider range of U.S. consumers and businesses, including those in locations that may otherwise be poorly served by more conventional broadband access networks.

5. By developing standards with global participation, the project will increase the chances of a uniform global result with broad export market opportunities.

\section{NIST's Role as Viewed from Survey Results}

As described above, NIST was active in organizing the IEEE 802.16 Working Group. Our survey considered how Working Group participants viewed NIST's participation. For example, we wondered how the development process would have been different had NIST not played this role. According to our survey, 10 percent of respondents said that, in this case the standard would not have been developed. Another 20 percent said the standard would have been developed later; the remaining 70 percent answered “other”. Within this 70 percent, however, NIST's leadership role was recognized as demonstrated by the following text comments: 
- "We won't guess the impact to timing, but at the very least federal support demonstrates commitment to other regulatory domains, which encourages global harmonization."

- "IEEE recognizes contributions from individuals. The Working Group Chair when he was at NIST contributed greatly to 802.16."

- "In a fiercely competitive environment, NIST was a neutral facilitator."

- “NIST's leadership and involvement allowed the standard to be developed in a much less biased environment than is typical with standards. It served to protect companies, especially small ones, from domination by other companies.”

- "NIST leadership enabled development of 802.16 within the arcane rules of IEEE without it becoming subject to miscreant forces."

- "Several proprietary systems would be deployed making the cost high and business case difficult (without mass market wireless broadband is challenging).”

One theme that came through in many of the comments was the ability of NIST to act as an unbiased facilitator and to level the playing field among companies of different sizes. Not many ventured a guess as to how long the standard would have been delayed without NIST's participation, but those who did estimated from one to two years.

With regard to whether NIST's participation affected industry participation in the 802.16 Working Group, 20 percent of the respondents stated that without NIST's leadership and involvement, industry participation would have been less; 40 percent thought it had little impact; and 40 percent did not know or did not answer.

\section{Other Factors}

Other factors that were considered important by the survey respondents as promoting the development and adoption of the WiMAX standard include the backing of large industry players, in particular chip makers, not having the technology or standard beholden to a single firm's intellectual property, and the role of the WiMAX Forum in certification and commercialization of the technology.

All of the surveyed firms belong to the WiMAX Forum, and 90 percent participate actively. Most respondents indicated that they saw WiMAX Forum take the lead on pursuing a related and expanded set of issues required for commercialization. With time, the WiMAX Forum has adopted its testing program to accommodate the latest developments in the standard, which has itself been evolving as a result of frequent amendments and revisions. In addition to the importance of getting products certified, key drivers for participation that were mentioned by a number of respondents are marketing benefits and participation in defining interface and interoperability details. 


\section{Costs of Developing the 802.16 Standard}

Companies and government organizations are generally cognizant of the costs involved with developing a standard, certainly more so than with the benefits that accrue to them as a result of participation. We have attempted to estimate the total cost of developing the IEEE 802.16 standard since the first official session of the Working Group was held in 1999. Although there had been several meetings of a predecessor group that evolved into the 802.16 Working Group, the cost estimate is focused on development efforts from the time the official Working Group was formed through the end of 2006.

From 802.16's inception in May 1999 through June 2006, NIST participated in every meeting, with a minimum of one attendee. This was essentially a full-time effort for the Chair of the Working Group. The NIST cost of participation included the fully loaded salary for the Chair of the Working Group, travel expenses, management oversight and administrative support. Several guest researchers also supported this effort. For the eight-year period, the NIST cost was just under \$3.0 million. ${ }^{\mathrm{xx}}$

Private sector cost in any standards group is always an issue and may act as a barrier to entry. A total of 47802.16 sessions were held from the very first session in May 1999 until the final session of 2006. The total number of attendees at these sessions was 7,490. (This is not the number of participating individuals since one person would often attend more than one session.) A total of 730 companies participated in the 802.16 Working Group during that time, representing 28 countries $^{\mathrm{xxi}}$ xxii. No company participated in all of the sessions, and the list of participating companies changed significantly from the early days of 1999 to the present. Company participation averaged approximately 10 sessions.

From our survey results and data available on the 802.16 website, we attempted to estimate the costs of participation by firms in the IEEE 802.16 Working Group. The companies of the survey respondents sent an average of 93 participants to the Working Group sessions over this time period with a median value of 65 . The average total amount spent by firms in our survey was $\$ 942,000$, with a much lower median figure of $\$ 180,000$. Respondents were asked to include the costs of staff and/or consultant's time, fees, travel expenses and overhead. The reported range was $\$ 100,000$ to $\$ 3$ million. There are, of course, many small firms that participated infrequently during this period; their costs would be substantially lower, especially if they were primarily observers.

These figures are then used to estimate the total cost for both NIST and the private sector participants to develop the IEEE 802.16 series of standards through 2006. As summarized in Table 1, the total cost is estimated to be $\$ 206.5$ million. .xiii The $^{2}$ government's costs are approximately one percent of the total. The Working Group activity peaked in 2004 and 2005 before declining slightly in 2006. It has since ramped up again in 2007. 
Table 1. Total Cost of Participation in the IEEE 802.16 Working Group (thousands)

\begin{tabular}{|c|r|r|r|}
\hline \multicolumn{1}{|l|}{ Year } & \multicolumn{1}{|c|}{ NIST } & \multicolumn{1}{c|}{ Private } & \multicolumn{1}{c|}{ Total } \\
\hline 1999 & $\$ 354$ & $\$ 9,438$ & $\$ 9,792$ \\
\hline 2000 & $\$ 369$ & $\$ 23,909$ & $\$ 24,278$ \\
\hline 2001 & $\$ 376$ & $\$ 22,930$ & $\$ 23,306$ \\
\hline 2002 & $\$ 390$ & $\$ 13,219$ & $\$ 13,609$ \\
\hline 2003 & $\$ 404$ & $\$ 12,621$ & $\$ 13,025$ \\
\hline 2004 & $\$ 396$ & $\$ 42,677$ & $\$ 43,073$ \\
\hline 2005 & $\$ 415$ & $\$ 44,308$ & $\$ 44,723$ \\
\hline 2006 & $\$ 161$ & $\$ 34,626$ & $\$ 34,787$ \\
\hline Total & $\$ 2,865$ & $\$ 203,728$ & $\$ 206,593$ \\
\hline
\end{tabular}

The commitment of companies varied over the years as to the level and number of participating staff, as well as the years of involvement. In our survey, we found that many firms track and assign their costs in different ways so the margin of error for this figure might be large. However, it is the firm's own perception of its cost of participation that is important. As such, a direct comparison of the figures may not be appropriate for detailed analysis. However, the self-reported figures do help to capture what the respondents think they have spent or contributed to this effort as a cost of doing business. NIST's total cost is calculated at slightly more than one percent of the total cost of development. However, taking into account the views of the survey respondents, one can argue that NIST's impact was much is greater than that. One way to place a value on this is to estimate the total cost of the standard development had NIST not positively influenced and possibly accelerated the process. How many more meetings would have been required, and what would the total added cost be in that case?

\section{Overview and Evolution of the WiMAX Market}

\section{Status today}

This section attempts to demonstrate that the market for WiMAX is broad and global. Pre-WiMAX technology has been around for a few years as a fixed wireless access medium, but it was never widely adopted, perhaps because it was being provided by different vendors using their proprietary technologies. Prior to any significant adoption of WiMAX, broadband wireless access (BWA) in 2005 generated worldwide service revenues totaling $\$ 1.8$ billion and equipment revenues of $\$ 750$ million. ${ }^{\text {xiv }}$ xxv Most of the equipment sold in 2005 was non-conformant or proprietary technology. However, WiMAX is gaining traction in the marketplace since adoption of the industrywide standard enables both service providers and technology vendors to make commercial commitments to the technology, forming the foundation of a WiMAX ecosystem. During 2006, service provider trials moved into launch phase in many areas. Analysts estimate that WiMAX service revenues in 2006 were in the hundreds of 
millions of dollars and that equipment revenues ranged from $\$ 143$ million $^{\text {xxvi }}$ to $\$ 549$ million ${ }^{\text {xxvii }}$.

In the first quarter of 2007 the number of deployments using proprietary technology has been falling. Only $52 \%$ of the deployments used proprietary technology, while 36 percent applied the 802.16-2004 (fixed) standard and 12 percent applied the 802.16e-2005 (mobile) version. ${ }^{\text {xxviii }}$ It is anticipated that WiMAX chipsets will be embedded in laptops by 2008, in handheld devices by 2009, and in consumer electronics in 2010.

Testing and certification of fixed 802.16-2004 technology has been underway; as of September 2007, over 30 products have been certified. The WiMAX Forum expects mobile WiMAX products to begin to be certified in 2008. In Wave 1 of mobile WiMAX certification, the initial systems to achieve certification will be based on a $2.3 \mathrm{GHz}$ profile with single-input, single-output (SISO) antenna systems. Wave 2 will follow in covering $2.5 \mathrm{GHz}$ systems with multiple-input, multiple-output (MIMO) and beam-forming antenna systems, important for enhanced indoor coverage and throughput. The assurance of quality through certification by independent testing is an important aspect of the expected success of WiMAX as it gives consumers confidence that these products are compliant to the standard and perform as advertised.

\section{International Market}

Europe is a large market for WiMAX-ready deployments and commercial trials, particularly of the fixed variety. The largest-scale individual projects are in the United States and parts of Asia (figure 1). By the first quarter of 2007, the U.S. had the most wireless broadband subscribers in the world, but only 17 percent of the deployments. ${ }^{\text {xxix }}$ Australia is quite advanced, and many announcements of new trials or deployments are occurring in Africa, the Middle East and Latin America. The WiMAX Forum is tracking 270 trials and deployments in more than 65 countries. ${ }^{\mathrm{xxx}}$ Fixed WiMAX may have a good market in the developing markets of Asia with low broadband penetration rates, such as China, Malaysia, India and Indonesia. Internationally, the growth of WiMAX is being driven by business customers and high-end residential users. The potential for use of 802.16 in the Chinese market is unclear; the government there has recently been pushing an alternative proprietary technology called McWiLL (Multi-carrier Wireless Internet Local Loop). ${ }^{\mathrm{xxi}}$ 


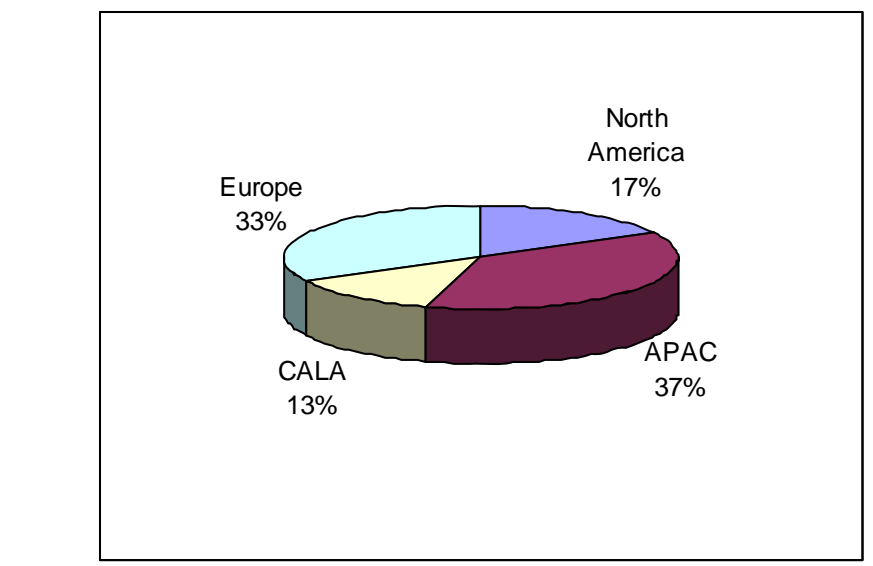

Figure 1 Percentage of WiMAX Deployments by Region (2007) ${ }^{\mathrm{xxxii}}$

\section{United States Market}

There currently exists a "comfortable duopoly of DSL and cable" in the United States, with 98 percent of the broadband market covered by them. ${ }^{\text {xxxiii }}$ WiMAX will enable two types of broadband offers - fixed broadband as a substitute to DSL and cable services, and mobile broadband as an upgrade or complement to such existing 3G technologies as Evolution, Data Optimized (EV-DO) and High-Speed Downlink Packet Access (HSDPA). Many operators holding $2.5 \mathrm{GHz}$ frequencies are proposing a quadruple play based almost entirely on broadband wireless (featuring WiMAX) as an alternative to traditional incumbent ${ }^{\mathrm{xxxiv}}$ operators. Initially most of the growth was anticipated to be in rural areas, where only about a quarter of the households have access to adequate broadband infrastructure. ${ }^{\mathrm{xxx}}$ However, that has been changing recently with more focus on urban areas by companies including Sprint-Nextel, the largest U.S. owner of spectrum targeted for WiMAX. Many analysts predict that business users, primarily the mobile employee or "road warriors", and high-end residential users will drive the market for WiMAX products and services, at least initially. ${ }^{\text {xxvi }}$

WiMAX is also starting to be used for municipal networks. Grand Rapids, Michigan is implementing the first large-scale, municipal mobile WiMAX deployment in the country; it was expected be available by the end of 2007 (see Appendix 2 for details). This will also be the first WiMAX/Wi-Fi hybrid network. Many other municipalities are following suit and are focused on enhancing public safety, provision of city services, and improving technology availability. For public safety applications, the need for video capabilities is the driver for broadband wireless growth. A further more detailed discussion of the U.S. municipal wireless market follows in section $\mathrm{X}$. 


\section{WiMAX Forecasts}

In view of the above, the market for WiMAX is expected to undergo rapid growth in the near-medium term. The potential market is very large. There are currently approximately half a million WiMAX subscribers worldwide. According to analyst estimates, the total addressable market for fixed wireless broadband in the United States is estimated to reach 87 million residences by 2011, while the mobile market will reach 161 million people in the same time frame. ${ }^{\text {xxxvii }}$ An estimate of this growth is provided in Figure 2, which displays the expected total number of accumulated WiMAX subscribers of 67.4 million worldwide, with the large majority (75\%) expected to be users of systems based on 802.16e-2005. Even with this growth, it appears that it will take several years before WiMAX becomes a mass market solution with tens of millions of users.

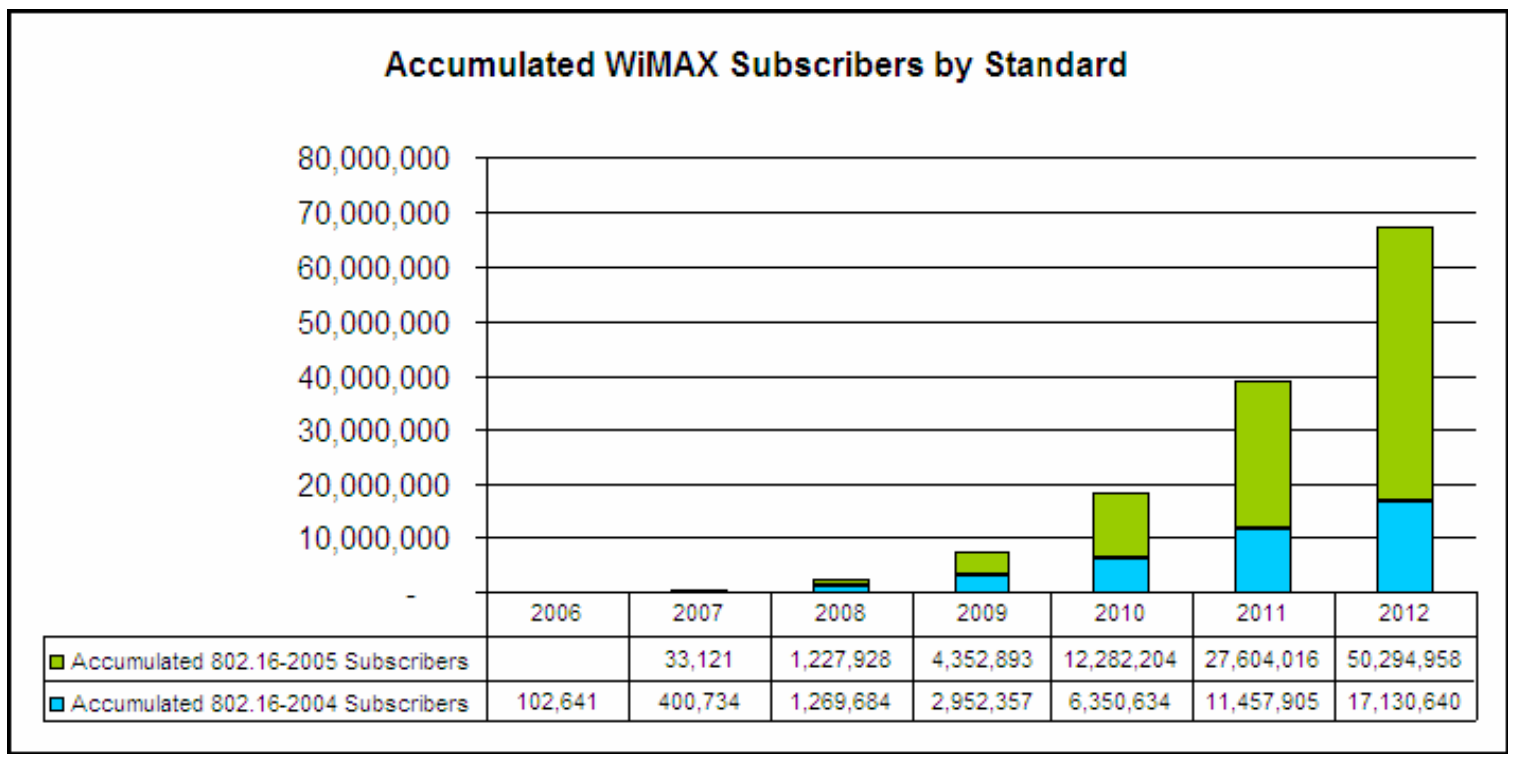

Figure 2 Accumulated Subscribers by Standard 2006-2012 (source: Maravedis) ${ }^{\mathrm{xxxviii}}$

A corresponding increase is anticipated in WiMAX equipment sales. Analysts forecast the market to grow from the hundreds of millions of dollars in 2006 to several billion dollars by the 2010-2012 timeframe. The range of estimates is demonstrated in Figure 3, which shows the forecasts from three research firms. Service revenues are estimated to be even larger. According to analyst forecasts, this figure will grow from \$2.6 billion in 2007 to $\$ 32$ billion in 2012. ${ }^{\text {xxix }}$ Much of this anticipated growth will be driven by $802.16 \mathrm{e}$ as it is expected to become the dominant WiMAX technology beginning in 2008. ${ }^{\mathrm{xl}}$ Although the individual analysts' forecasts differ, most expect strong WiMAX growth and adoption. ${ }^{\text {xli }}$ These figures demonstrate that potentially large economic impact is anticipated even using the more conservative estimates. 


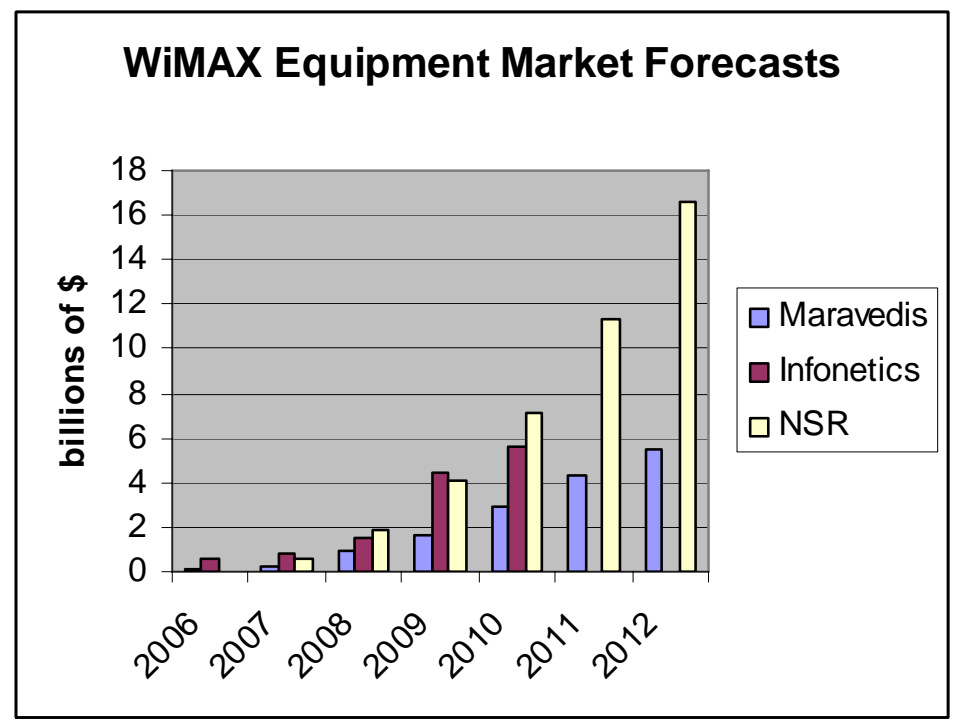

Figure 3 Annual WiMAX Equipment Market Forecasts ${ }^{\text {xlii }}$

\section{Benefits}

\section{Identify actors and stakeholders}

Our approach involves 1) identifying and classifying the various stakeholders and aggregating them to high-level groups; 2) identifying and classifying various benefits and costs associated with operationalizing WiMAX technologies; and 3) indicating which stakeholder groups are affected by which benefits and costs. ${ }^{\text {xliii }}$

For the purposes of this report, stakeholders in WiMAX are aggregated as Operators, Legacy Incumbents, Vendors/Manufacturers, Standards Organizations, Governments and End Users. These different stakeholder groupings are described as follows.

Operators. Operators include the subscription service providers for telephony, communication, data, and other network services to end users. Some of these are major phone and internet service providers whose networks cover huge areas, while others can be small and specialized, both in regional area and in customer base.

Legacy Incumbents. These are existing fixed voice and data service providers using current technologies. These incumbents include both wired networks (DSL and cable, and to a lesser extent fiber optics), and Wi-Fi-based wireless networks. Such incumbents might benefit from their installed client base and business models, but on the other hand may face losses due to early obsolescence of their capital equipment and other infrastructure. 
Vendors/Manufacturers. These include makers and marketers of chipsets, devices, base stations and servers, peripherals, but also software and operations, and consulting services to owners and operators of communications systems. This group also includes vendors of test and certification systems for WiMAX products.

Standards Organizations. Standards development organizations and standards setting organizations develop families of standards. IEEE is the dominant SDO stakeholder in this group, with the 802.16 standard for WiMAX.

Governments. A key metric for inter- and intra-national comparisons is the depth of broadband connectivity within countries. Governments therefore have a public policy interest in broadband projects. Local governments are critical in establishing municipal wireless broadband networks, a rapidly growing market. U.S. States are also getting in the game in a big way. Massachusetts has announced a \$25 million broadband initiative fund to connect the state's last mile areas by $2010 .{ }^{\text {xliv }}$ The program is platform-neutral, but it is logical to expect WiMAX to be a significant player. Ohio has a similar thrust as part of its NexGen network.

End Users-Business. Business customers are concerned with bandwidth, security, and quality of service (QoS) of the communications services they contract for (this stakeholder group would also account for Government end users).

End Users-Public. Public end-users, whether household or individual, are critical to the success of any technology-based service in that return on investment depends on subscriber-generated revenue. Likewise, sales of WiMAX-embedded consumer devices (Personal Digital Assistants, cameras, laptops, etc.) are driven by numbers of subscribed public end users. 


\section{Identifying benefits, costs, risks}

The benefits of WiMAX are multiple and manifest and accrue to multiple stakeholders. In both fixed and mobile applications, WiMAX offers greatly increased range and bandwidth, offering promise for bundled data and communications capable of high-end tasks such as telephony, video, and fast browsing in single devices. The extended range of WiMAX, compared with competing technologies, promises broader network coverage with lower capital outlay and operating costs. Enhanced security capabilities draw government and business users, increasing their efficiencies. Current global interest and activity in WiMAX projects by operators, vendors, and governments indicate the very high potential this technology has for improved performance and reduced costs.

On the other hand, WiMAX is a disruptive technology, meaning that holders and operators of legacy technologies (Wi-Fi, DSL, cable, cellular, etc.) face the threat of loss of market share. Also, while WiMAX performance benefits have been demonstrated in small pilots, real world effects may restrict its utility in large, complex systems limiting its use as a large wide-area network with many users. Business and management systems

may not be equipped to properly implement the new hardware and software. Standards friction may result in the presence of proprietary WiMAX-like networks, resulting in non-interoperability. Once the gleam is off the new services, subscribers may not contract in sufficient numbers to give good return on investment.

Table 2 identifies the primary perceived benefits of WiMAX systems and applications and which stakeholder groups enjoy these. In a similar way, Table 3 summarizes the costs and risks associated with WiMAX. 
Table 2 Stakeholders Potentially Affected by Benefits/Cost Savings.

\begin{tabular}{|c|c|c|c|c|c|c|c|}
\hline Type of Benefit or Cost Saving & 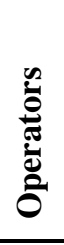 & 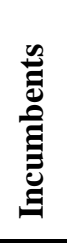 & 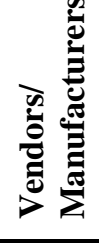 & $\begin{array}{l}n \\
0 \\
\infty \\
\infty \\
0 \\
0 \\
\text { के }\end{array}$ & 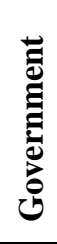 & 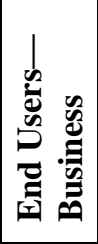 & 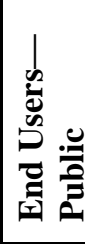 \\
\hline $\begin{array}{l}\text { 802.16 standards accelerates WiMAX development } \\
\text { and adoption }\end{array}$ & $\sqrt{ }$ & & $\sqrt{ }$ & $\sqrt{ }$ & $\sqrt{ }$ & $\sqrt{ }$ & $\sqrt{ }$ \\
\hline Standards participation increases ROI & $\sqrt{ }$ & & $\sqrt{ }$ & & & & \\
\hline $\begin{array}{l}\text { Fixed WiMAX enables "last mile" connectivity and } \\
\text { service }\end{array}$ & $\sqrt{ }$ & $\sqrt{ }$ & & & $\sqrt{ }$ & $\sqrt{ }$ & $\sqrt{ }$ \\
\hline Fixed WiMAX is efficient in backhaul operations & $\sqrt{ }$ & $\sqrt{ }$ & $\sqrt{ }$ & & $\sqrt{ }$ & $\sqrt{ }$ & $\sqrt{ }$ \\
\hline $\begin{array}{l}\text { Fixed WiMAX covers more area than Wi-Fi at lower } \\
\text { capital cost per user }\end{array}$ & $\sqrt{ }$ & & $\sqrt{ }$ & & $\sqrt{ }$ & & \\
\hline $\begin{array}{l}\text { Mobile WiMAX enables efficient applications for } \\
\text { SCADA[?], security, other municipal operations }\end{array}$ & $\sqrt{ }$ & & $\sqrt{ }$ & & $\sqrt{ }$ & $\sqrt{ }$ & \\
\hline $\begin{array}{l}\text { Mobile WiMAX integrates mobile phone with high } \\
\text { bandwidth data }\end{array}$ & $\sqrt{ }$ & & $\sqrt{ }$ & $\sqrt{ }$ & $\sqrt{ }$ & $\sqrt{ }$ & $\sqrt{ }$ \\
\hline $\begin{array}{l}\text { WiMAX systems increase competition and improve } \\
\text { quality, availability, and affordability }\end{array}$ & $\sqrt{ }$ & & $\sqrt{ }$ & $\sqrt{ }$ & $\sqrt{ }$ & $\sqrt{ }$ & $\sqrt{ }$ \\
\hline $\begin{array}{l}\text { Creative business models create stronger services } \\
\text { (bundling) }\end{array}$ & $\sqrt{ }$ & & & & $\sqrt{ }$ & $\sqrt{ }$ & $\sqrt{ }$ \\
\hline Hybrid systems utilize legacy hardware, software & $\sqrt{ }$ & $\sqrt{ }$ & $\sqrt{ }$ & & & & \\
\hline Variety reduction leads to economies of scale & $\sqrt{ }$ & & $\sqrt{ }$ & & & & \\
\hline $\begin{array}{l}\text { Lower system integration costs due to content of } \\
\text { standards }\end{array}$ & $\sqrt{ }$ & & $\sqrt{ }$ & $\sqrt{ }$ & $\sqrt{ }$ & & \\
\hline Supplier alliances benefits small business & $\sqrt{ }$ & & $\sqrt{ }$ & & & & \\
\hline $\begin{array}{l}\text { Standards-based, common platform fosters rapid } \\
\text { innovation and the addition of new components and } \\
\text { services }\end{array}$ & & & $\sqrt{ }$ & & & & \\
\hline $\begin{array}{l}\text { Specialization (i.e. Base Stations or handsets) - no } \\
\text { longer need to create an entire end-to- end solution } \\
\text { as in proprietary model }\end{array}$ & & & $\sqrt{ }$ & & & & \\
\hline $\begin{array}{l}\text { Broadband services made available in areas that were } \\
\text { previously out of the broadband loop }\end{array}$ & & & & & & $\sqrt{ }$ & $\sqrt{ }$ \\
\hline $\begin{array}{l}\text { More players in the market translate into more } \\
\text { choices for broadband services }\end{array}$ & & & & & & $\sqrt{ }$ & $\sqrt{ }$ \\
\hline $\begin{array}{l}\text { Quick “trickle down” effect of cost savings to } \\
\text { consumers }\end{array}$ & & & & & & $\sqrt{ }$ & $\sqrt{ }$ \\
\hline $\begin{array}{l}\text { Common platform drives down costs, fosters } \\
\text { competition and encourages innovation }\end{array}$ & $\sqrt{ }$ & & & & & & \\
\hline $\begin{array}{l}\text { No commitments to single vendors of the proprietary } \\
\text { technology }\end{array}$ & $\sqrt{ }$ & & & & & & \\
\hline $\begin{array}{l}\text { Wireless systems significantly reduce operator } \\
\text { investment risk }\end{array}$ & $\sqrt{ }$ & & & & & & \\
\hline $\begin{array}{l}\text { Standardization creates a volume opportunity for } \\
\text { chip set vendors/silicon suppliers }\end{array}$ & & & $\sqrt{ }$ & & & & \\
\hline
\end{tabular}


Table 3 Stakeholders Potentially Affected by Increased Costs and Risks

\begin{tabular}{|c|c|c|c|c|c|c|c|}
\hline Type of Cost Increase or Benefit Reduction & 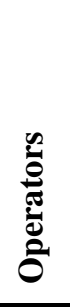 & 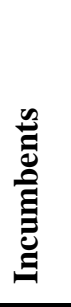 & 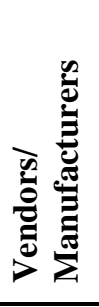 & $\begin{array}{l}\infty \\
0 \\
\infty \\
\infty \\
\infty \\
0 \\
0 \\
\infty\end{array}$ & 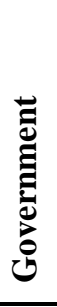 & 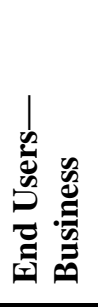 & 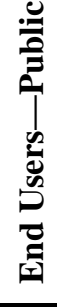 \\
\hline $\begin{array}{l}\text { "Real world" effects restrict WiMAX potential } \\
\text { (range, bandwidth, QoS) }\end{array}$ & $\sqrt{ }$ & & $\sqrt{ }$ & $\sqrt{ }$ & $\sqrt{ }$ & $\sqrt{ }$ & $\sqrt{ }$ \\
\hline $\begin{array}{l}\text { Business models not tested; revenue, profit may } \\
\text { not meet projections }\end{array}$ & $\sqrt{ }$ & $\sqrt{ }$ & & & $\sqrt{ }$ & & \\
\hline ARPU may not be sufficient for good ROI & $\sqrt{ }$ & & & & $\sqrt{ }$ & & \\
\hline Chipset power consumption difficult to solve & $\sqrt{ }$ & & $\sqrt{ }$ & $\sqrt{ }$ & & $\sqrt{ }$ & $\sqrt{ }$ \\
\hline Competition threatens operators of legacy systems & $\sqrt{ }$ & $\sqrt{ }$ & & $\sqrt{ }$ & $\sqrt{ }$ & & \\
\hline Available spectra may be limited or costly & $\sqrt{ }$ & $\sqrt{ }$ & & & $\sqrt{ }$ & & \\
\hline
\end{tabular}

\section{Private (industry) Benefits}

WiMAX has been gaining traction in the marketplace because the establishment of the 802.16 standard enabled both service providers and technology vendors to make commercial commitments to the technology, thereby forming the foundation of a WiMAX industry ecosystem. This technology is becoming a major component of the broadband wireless industry. The standard has created opportunities to expand the size of the market. Although three years have passed since the adoption of 802.16-2004, significant market impact is only in the beginning phases. The initial results, in terms of market success achieved by specific industry actors, are not readily available, hence the ability to conduct a quantitative analysis on revenues (or cost savings) attributable to the standard is limited.

It is expected that WiMAX will increase revenues for the companies participating in the new ecosystem. Projected revenue estimates were not provided by our survey respondents except for one firm, and the answer it gave was very general. However, six of the respondents stated that the 802.16 standards effort has hastened adoption of WiMAX technology, and therefore have accelerated revenues or cost savings for the company. Four stated an acceleration of 1 to 2 years, while two suggested an acceleration of 3 or more years, pointing out that there might have been very little adoption at all without a consensus standard. Only one stated that there was no acceleration, while the others did not know or did not answer. Figure 4 displays the results. 


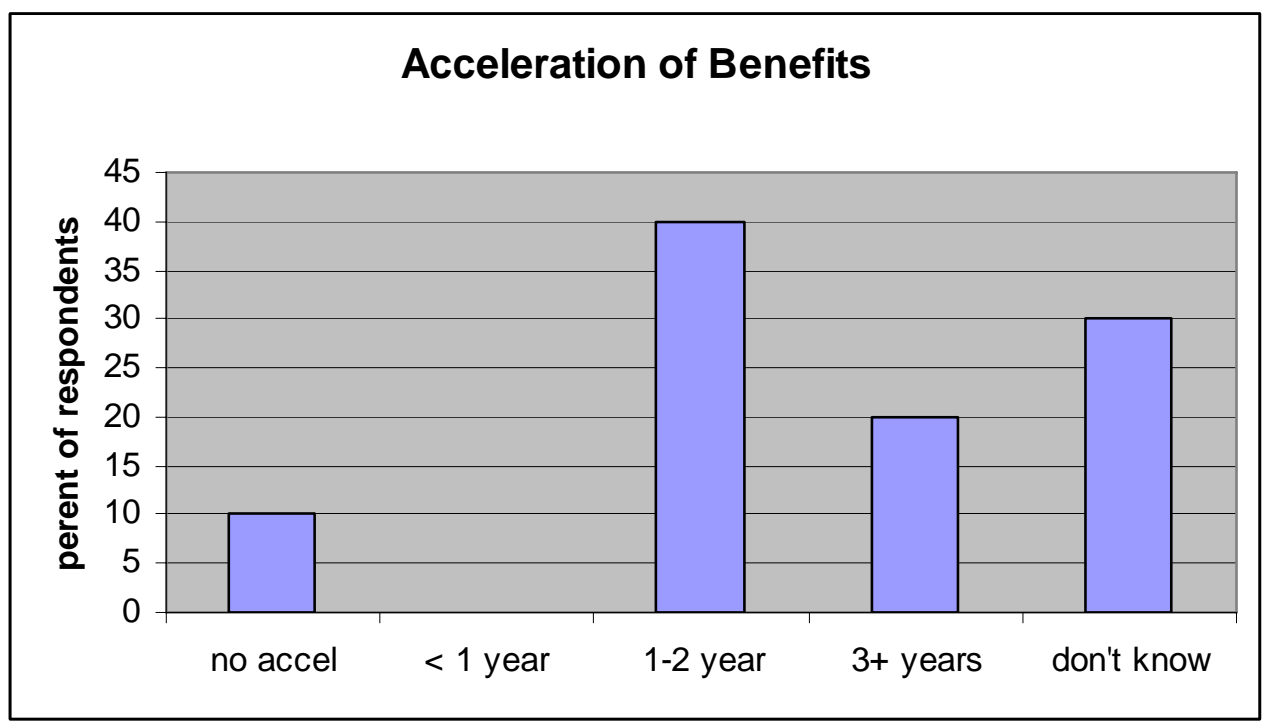

Figure 4 Estimate of the Acceleration of Benefits Due to the 802.16 Standard

According to our survey respondents, market access/creation was the largest single benefit of adopting the 802.16 standard for their companies, as identified by 8 of the 10 respondents. The second and third most common benefits related to supply chain flexibility and to mix-and-match interoperability (see Figure 5).

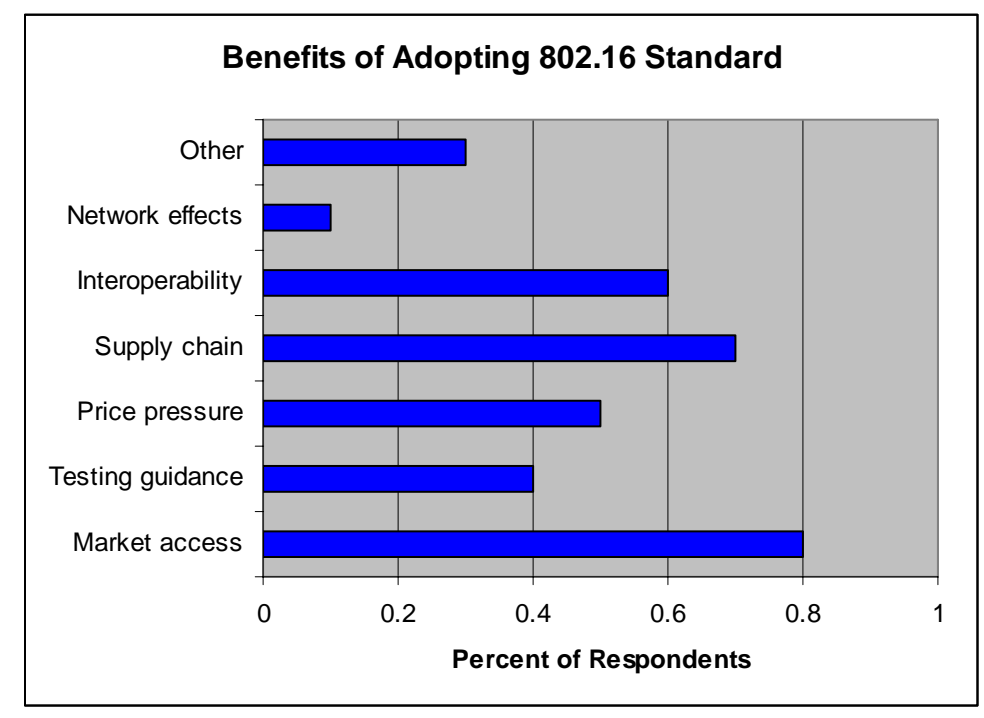

Figure 5 Survey Results of the Benefits of Adopting the 802.16 Standard

Some of the reasons given by respondents stating market access as being most important include:

- Wireless broadband has had some false starts and there needs to be a success; 
- The market controls the rest of the variables;

- Because the uniqueness of 802.16 vis-à-vis other mobile wireless standards is that it was developed as part of the same larger body IEEE 802 that made 802.3 and 802.11 and also had the most OFDM expertise to date in terms of products

- Without a market others factors won't matter much

Another key benefit of the standard is increased efficiencies. These can manifest themselves in a number of ways. Within the WiMAX industry, some of these include reduction of barriers to new entrants, evident from the large number of firms that participated in the IEEE 802.16 process as well as the very large membership of the WiMAX Forum, which includes many small companies.

From a business case perspective, the throughput and sectoral efficiency advantages of mobile WiMAX results in fewer base stations to achieve a desired data density. Fewer base stations will reduce the network capital costs for a given network capacity, and with lower equipment maintenance costs, lead to lower operating expenses. xlv

Pre-WiMAX technology has been around for a few years as a fixed wireless access medium, but was never widely adopted because it was provided by different vendors using their proprietary technologies. This made switching between vendors/companies difficult as the networking gear of one vendor could not seamlessly talk to another. The WiMAX standard has allowed for interoperability between products from different vendors, which also drives down cost.

Survey respondents who stated that interoperability was the most important benefit of the 802.16 standard commented that it:

- Leads to most other items, such as price pressure, market creation, etc.

- Provides us with reassurance that equipment will perform to known capability without the need to undertake full interoperability testing

\section{Social/Public Benefits}

The societal benefits of WiMAX accrue to government or other institutions, to individuals, or both. Early evidence suggests significant government savings due to WiMAX systems. Allegany County, MD, which installed a pre-WiMAX system (a bridging technology) to provide high-speed Internet access to the county's government buildings, schools and libraries, is saving $\$ 560,000$ in operational and telecommunications costs. ${ }^{x l v i}$ One of the biggest potential benefits to individual consumers is the availability of bundled high-speed internet voice and data service, accessible with multiple devices, at a set price. Currently, broadband data service via DSL or cable costs approximately $\$ 40$ per month, while unlimited 3G access to the Internet via an EV-DO network costs about $\$ 60$ to $\$ 80$ per month. ${ }^{\text {xlvii }}$ 
In a recent survey commissioned by Motorola, the top four anticipated internet uses for mobile WiMAX are: reading or responding to email (49\%); reading and watching "live" online news (31\%); watching and listening to mobile entertainment such as mobile TV (28\%); and downloading and listening to music (28\%). ${ }^{\text {xlvii }}$ If a bundled WiMAX single-fee service can be delivered at a pricing point within the range of existing data services, then price is not predicted to be a major factor for many potential customers. $^{\text {xlix }}$

Full adoption of such services by significant numbers of consumers requires a wide selection of devices that can connect to the service. The WiMAX industry is now promoting new mobile devices with advanced functionality to support high-speed handoffs, roaming, and multiple antenna technologies. Initial mobile WiMAX equipment will include notebook-based subscriber units (mini PCMCIA cards, PCI Express, USB modules, etc.) and desktop units.

Reseeding the market with new devices takes about 18 to 24 months, which will have an impact on adoption. ' The introduction of mobile devices with embedded WiMAX connectivity, such as notebooks, the Ultra Mobile PC (UMPC), PDA's, smart phones and other wireless devices, is expected to emerge in 2008. In addition to VoiceOver IP (VoIP), other real-time applications like mobile video and audio streaming, videoconferencing, and gaming will greatly benefit from the QoS and low latency offered by WiMAX.

Large-scale consumer adoption benefits government and enterprise users as well, since vertical applications, such as surveillance, public safety, connectivity to remote devices, inventory fleet tracking, fleet management and educational services, are also supported by mobile WiMAX network with little or no incremental cost to network operators.

\section{Digital Divide}

WiMAX, along with Wi-Fi and VoIP, have been identified as enabling technologies that allow access to ICT to be expanded to rural areas, with improvements in the speed and quality of service in unserved and underserved areas at an acceptable price-point. These deployments do not require significant capital investment, are environmentally green, and have low operating costs. Early experience, gained through several demonstration networks in developing countries, indicate that a reasonably-sized community can be provisioned for a capital investment on the order of $\$ 25,000$ to $\$ 40,000$. $^{\text {li }}$

An unserved area can be defined as one where residents and businesses are unable to obtain broadband connectivity at prices, level of service and quality of service levels comparable to served areas. There are approximately 1.5 billion people in 800,000 villages without connection to Information and Communication Technologies (ICTs). According to a recent United Nations Conference on Trade and Development 
(UNCTAD) report, the Digital Divide is narrowing when it comes to basic access to the Internet and mobile phones but it taking on new forms in terms of the differences in the speed and quality of access to ICTs. The information and content gap is still growing. ${ }^{\text {lii }}$ Standards can be an important tool for bridging the divide and spurring economic development. If firms in poor and developing countries can opt for these technical advances represented in that technology, the standards can then provide an important means for the technological catch-up process in such countries. ${ }^{\text {liii }}$

An example of an initiative in the developing world, U.S. Agency for International Development (USAID) and Intel in 2005 launched a Last Mile Initiative (LMI) in Vietnam. This is part of an ongoing USAID Last Mile Initiative established in 2004 aimed at expanding telecommunications into rural areas of developing countries. During 2006 and 2007, together with a local partner, Vietnam Data Communications (VDC), WiMAX technology was installed in Lao Cai, a city in the rural northern Vietnam where telecommunications services are limited, as well as in a second, more rural site (Ta Van Commune) to provide high-speed broadband and telephone service. One of the primary goals of the project is to provide a robust economic relationship with neighboring trading partners through the use of the new telecommunications infrastructure. There is also an educational focus since, in the deployment in Lao Cai, five high schools and secondary schools are targeted to receive local-language ICTrelated curriculum. ${ }^{\text {liv }}$ An impact assessment was launched for the LMI initiative beginning in October 2006. Baseline data has been collected from the two project sites. Data gathering and analysis for outcomes was not yet completed at the time of this report. What has been demonstrated to date is that this is a successful model of a public-private partnership between industry (Intel), government (USAID), and a local partner (VDC). Many other examples of the use of WiMAX as well as other broadband wireless technologies to bring telecommunications services and broadband internet to rural agricultural centers have been termed a "rural revolution". lv

The digital divide is not just an issue for developing nations. Pockets and large sparsely-occupied areas of developed countries also have this issue. WiMAX will be a key component of a national broadband network to be developed by the Government of Australia, called Australia Connected, to provide 12 Megabytes per second broadband services to rural and regional communities with the goal of ensuring that 99 percent of the population has access to fast affordable broadband by June 2009. ${ }^{\text {lvi }}$ Of Australia's 20.8 million people, 3.1 million live in rural areas.

In the United States., a widely reported figure from the Pew Internet Project states that $47 \%$ of American adults have broadband at home, up from 42 percent a year earlier, but still behind many other developed countries. ${ }^{\text {lvii }}$ In rural areas, the broadband adoption rate is reported to be only $31 \%$, lagging adoption rates of $52 \%$ and $49 \%$, respectively, in urban and suburban communities. Presumably, WiMAX, with its long range and high quality of service, would be a good candidate technology for adding fixed broadband service to last-mile customers. ${ }^{\text {lviii }}$ 
There are many examples of WiMAX commercial services being announced to fill the void where broadband is difficult to get. The U.S. Department of Agriculture rural broadband program has made over 70 loans totaling $\$ 1.2$ billion in 40 different states for communities with populations less than 20,000. It now also considers WiMAX technologies for funding. ${ }^{\text {lix }}$ Many operators are planning to use WiMAX to reach the unserved and underserved markets. One company, DigitalBridge, was founded recently specifically to deliver broadband service to such communities using WiMAX technology. It has targeted seven states with large rural areas for its first phase of operations.

\section{Projected U.S. Municipal Wireless Market}

This analysis of the U.S. market prospects for WiMAX focuses on municipal wireless broadband applications.

The degree of penetration of broadband services in the United States which is very high does not indicate the number of connected citizens since only approximately 47 $\%$ of U.S. adults have broadband service in their residence. ${ }^{\mathrm{lx}}$ Such a lag in utilization of broadband cannot be accounted for by only physical disconnectedness; presumably, price and quality of service, coupled with socio-economic factors, deter full subscription to available service in otherwise highly connected regions, specifically relatively high density suburban and rural areas.

Many municipalities in the United States are exploring policies to develop competitive, high-speed wireless broadband services as a means of increasing connectedness, facilitating government services, and improving attractiveness to business. For these reasons the municipal wireless broadband market in the United States represents an early stage, large potential and rapidly growing market. Wi-FiWi-Fi has been widely used since about 2002 for wireless broadband in local government and public networks, but the much greater range and higher data-transfer speeds of WiMAX will drive its emergence as a wide-area broadband infrastructure solution for local authorities.

The MuniWireless State of the Market Report, 2006, based on a survey of market participants in municipal wireless networks, describes the U.S. municipal wireless market and gives the basis for a market forecast for the period 2007-2010. ${ }^{\text {xi }}$ That report centers on four segments-large, medium, and small cities, and counties. Combining the resulting projections with actual market data yields the expenditure and growth figures in Table 4. These cost numbers reflect hardware and software, training, maintenance and support, and other direct costs, but do not include internal staff costs for the municipalities. According to MuniWireless, $44 \%$ of these total expenditures go to actual system hardware, software, and devices. 
Table 4 Actual and projected market for US Municipal Wireless [MuniWireless, 2006]

\begin{tabular}{|l|c|c|c|c|c|c|}
\hline & $\mathbf{2 0 0 4}$ & $\mathbf{2 0 0 5}$ & $\mathbf{2 0 0 6}$ & $\mathbf{2 0 0 7}$ & $\mathbf{2 0 0 8}$ & $\mathbf{2 0 0 9}$ \\
\hline $\begin{array}{l}\text { Total } \\
\text { Spending } \\
(\$ \mathrm{M})\end{array}$ & 47.4 & 116.9 & 235.5 & 459.6 & 941.0 & 1757.5 \\
\hline $\begin{array}{l}\text { System } \\
\begin{array}{l}\text { Spending } \\
(\$ \mathrm{M})\end{array}\end{array}$ & 20.9 & 51.4 & 103.6 & 202.2 & 414.0 & 773.3 \\
\hline $\begin{array}{l}\text { Annual } \\
\text { Growth (\%) }\end{array}$ & -- & 147 & 102 & 95 & 105 & 87 \\
\hline
\end{tabular}

\section{Estimating WiMAX share}

It is of course difficult to predict the share of the projected U.S. municipal wireless broadband market that WiMAX is likely to acquire over the short term.

Nevertheless, the perceived advantages of WiMAX over Wi-Fi-increased range, improved QoS, broader spectrum, and others - are expected to drive rapid implementation of WiMAX. Coupled with the trend of wireless broadband efforts toward larger cities and county regions, where the range of WiMAX networks gains advantage over mesh Wi-Fi networks, the user-equipment market creates even more impetus for a shift towards WiMAX wireless broadband in U.S. cities. (By 2009, 79\% of the spending for municipal wireless in the United States will be centered in large cities and counties, according to MuniWireless projections).

Analysts estimate the WiMAX share of these markets by looking at what happened with satellite television in the United States, where the new technology grabbed over $12 \%$ of the market for paid TV within five years of commercialization in the 1990’s. ${ }^{\text {xii }}$

Using this historic achievement, one way to forecast the market for WiMAX in U.S. municipal wireless broadband is to apply a $10 \%$ share of the system expenditures forecast by the MuniWireless analysis shown in Table 4. However, recent trends suggest that this estimate may be too conservative.

Many cities have recently initiated or announced plans for WiMAX-based broadband systems. Many counties - and even states - are now rolling out broadband wireless initiatives that include WiMAX. For example, Oakland County in Michigan is implementing a hybrid broadband network that will include WiMAX, and the state of Rhode Island is rolling out a statewide Wi-Fi and WiMAX network. In addition to providing broadband wireless access to its citizens, many of these new systems are supporting municipal services. Examples of municipal applications include: 
- public safety

- education

- employee connectivity

- economic development

- health care

According to a survey by muniwireless.com, public safety is the top municipal application, with $65 \%$ of respondents stating that they have, or will have, a public safety application on their wireless broadband network. ${ }^{\text {lxiii }}$ Note that many of these applications are also feasible with alternative wireless networks, such as Wi-Fi. However, it is the authors' view that WiMAX will improve the capability of municipal and other governments to deliver such services due to the higher bandwidth and the ability for mobile applications.

Of particular interest, Grand Rapids, MI, is providing both municipal services as well as retail broadband services to its citizens, and is the first true 802.16e municipal wireless system in the country. This is described in detail in Appendix 2.

Also, from our survey, 40 percent of the respondents stated that they currently plan to support deployment of WiMAX for municipal services. Stated examples of services include as a backbone for Wi-Fi systems; as a complete municipal broadband system, and in specific niches such as public safety, homeland security, video surveillance, telematics, and remote utilities.

Finally, some major U.S. cities are rethinking or canceling their Wi-Fi plans and instead awaiting the availability of WiMAX wide-area networks. Chicago has canceled its planned city-wide Wi-Fi network, ${ }^{\text {lxiv }}$ while San Francisco and Houston have struggled to maintain agreements with vendors for planned Wi-Fi systems, primarily due to factors such as cost structuring, ROI goals, and anticipated technology improvements offered by WiMAX. ${ }^{\mathrm{lxv}}$ Wi-Fi and WiMAX can, however, coexist within hybrid systems in which Wi-Fi delivers wireless local area network coverage from data delivered via WiMAX, ${ }^{\text {lxvilxvii }}$

Given these trends, it seems reasonable to project that WiMAX technologies might account for $20 \%$ of the predicted U.S., municipal broadband market, or close to $\$ 150$ million by 2009. This assumption yields the revenue forecasts as shown in Table 5.

Table 5 Projected WiMAX system expenditures in US municipal wireless broadband

\begin{tabular}{|l|c|c|c|c|}
\hline & $\mathbf{2 0 0 6}$ & $\mathbf{2 0 0 7}$ & $\mathbf{2 0 0 8}$ & $\mathbf{2 0 0 9}$ \\
\hline $\begin{array}{l}\text { Forecast } \\
\text { System } \\
\begin{array}{l}\text { Spending } \\
(\$ M)\end{array}\end{array}$ & 103.6 & 202.2 & 414.0 & 773.3 \\
\hline $\begin{array}{l}\text { Projected } \\
\begin{array}{l}\text { WiMAX } \\
\text { Share (\$M) }\end{array}\end{array}$ & 20.8 & 40.4 & 82.8 & 144.6 \\
\hline
\end{tabular}


International government projects are also appearing. For example the Republic of Georgia is launching a WiMAX network intended to be used for providing government officials with VoIP services, internet access, and teleconferencing. ${ }^{\text {lxviii }}$ In France, the city of Rouen recently made an announcement regarding deploying a citywide WiMAX network which, in addition to its regular household and commercial customers, will provide the city with capabilities for remote management of municipal services, including emergency services and video surveillance. ${ }^{\text {lxix }}$

\section{Impact on Innovation and Competitiveness}

The relationship between standards and innovation is complex. Standardization may be supportive of innovation and an integral part of the process of innovation, while at other times standards may hinder or impede innovation. Standardization can sometime be the principal innovation. This is the case today in ICT, where standardization supports and coordinates innovations and helps to realize economies of scale. ${ }^{\mathrm{lxx}}$

In some cases, a standard precedes innovation by establishing a baseline for design and performance that will satisfy user requirements. That standard should provide enough flexibility that suppliers or manufacturers can modify features, function or price to establish a niche that positions them with a marketplace advantage. In other cases, innovation comes first, and the standard becomes the physical documentation of an agreed-upon solution that has already been tested and proven. Each industry and stakeholder group has unique needs, and in order to satisfy these needs, the approach must be fluid. ${ }^{\text {lxi }}$ Timing is an important issue. Too early, and a standard may effectively shut out promising and possibly superior technology, while if too late, the costs of transition to the standard may be too high, thus deterring diffusion. lxxii Blind has proposed that there is a dynamic dimension to standards because they play a crucial role in research and innovation, with various feedback loops along the research and development cycle from pure basic research through the diffusion of new products. Standards have different functions in the innovation process and may affect several economic aspects. ${ }^{\text {lxxiii }}$

In our survey, eight of ten survey respondents stated that the 802.16 standard promoted innovation (while two did not answer). This is not surprising because the development of the WiMAX standard fits the descriptions that most practitioners and academics have identified as characteristics of standards development that support innovation. Some of the reasons cited in our survey were:

- Certain optional features provide value added performance and promote innovation

- As with any new standard, it provides the framework, but implementation is what companies will work on to provide differentiation (i.e., field deployment metrics) 
- (Innovation) as such is inherently driven when a global industry ecosystem is created. Further, adoption of standards requires innovation if differentiation that creates value - as viewed by purchasers - is to be earned.

- (Innovation is promoted) by multiple technical experts from the fixed and mobile broadband wireless industry participating, and state of the art techniques being adopted into the standard (e.g.,. OFDMA, MIMO, etc)

- Companies are always competing to get their methods into the standard - the best usually win. The group works as a team to improve the standard based on market pressures.

- Through the development of the WiMAX environment.

- Standards like 802.16 do not necessarily provide innovation, but do promote competitiveness because everyone has access to similar capabilities within the ecosystem.

It is interesting that the creation and existence of a WiMAX environment or ecosystem were noted as being important for the role of innovation.

WiMAX is in the process of being rolled out in many countries in the developing world. One of the primary reasons for this is that they have little copper-wire infrastructure and cannot afford to begin to lay fiber connections. WiMAX will in essence be a leap-frog technology for much of the developing world. This allows these countries to compete on equal footing with the developing world in telecommunications platforms, to invite investment, and to promote economic growth in the country. The overall competitiveness of developing countries will be enhanced in the realm of globalization. ${ }^{\text {lxxiv }}$

\section{Other Trends and Indicators of Impact} includes:

A listing of other indicators of impact that are not easily categorized elsewhere

1. Popular Mechanics listed IEEE 802.16 as one of "The top 50 inventions of the past 50 years".

2. The WiMAX Forum has initiated a training certification program. Students will be certified in the WiMAX Professional Certification Program. The program has three certification tracks: network designer, network association, and network operator. The certification courses offer tutorials and practical hands-on training covering the IEEE 802.16 standard.

3. China Mobile confirmed that it will set up a WiMAX network for the 2008 Beijing Olympics.

4. Estonia is poised to become the first country completely covered by WiMAX. Four WiMAX licenses were auctioned off and one of the firms is set to have a nationwide roll-out completed by 2007 covering over $60 \%$ of the country. 
5. Singapore is establishing a WiMAX network (WISEPORT) to serve inbound ships by providing remote access to transhipment functions such as submitting documentation and filing requests for services. . $^{\mathrm{xxv}}$

6. As a disruptive technology, analysts predict that WiMAX may negatively impact broadcast and satellite radio as new automobiles are equipped with WiMAX broadband connectivity, giving drivers better options for access to music and other content traditionally delivered by radio. ${ }^{\text {lxvi }}$

\section{Challenges}

Two major criticisms of WiMAX have been that it does not apply to enough ubiquitous spectrum to be mass deployable, and that it has not been tested yet in realworld situations with large numbers of users. Key issues include how much spectrum remains available in any given country, how the spectrum is allocated, and how much spectrum is controlled by incumbent carriers. In the United States, only one or two companies currently have adequate spectrum to be able to build a truly national network. The Sprint-Nextel and Clearwire partnership which aimed to create a joint national network in the United States was recently terminated. It is not yet known if the final pricing point of bundled services will be competitive with conventional broadband service plans. The commercial roll-out of WiBro in South Korea, which is a version of WiMAX, has gotten off to a slow start despite the active participation of South Korean firms in the development of WiMAX. ${ }^{\text {lxxvii }}$ The time and investment required to fully deploy the technology is large and companies have to be willing to make the commitment.

As a disruptive standard, WiMAX adoption will be challenged by pushback from supporters of competing technologies such as Wi-Fi. However, both standards will benefit from integrated WiMAX/Wi-Fi devices that are targeted for low-power, wide frequency range applications. ${ }^{\text {lxxviii }}$

Other existing and evolutionary technologies may limit WiMAX adoption. A rival technology with the potential to work well in high velocity mobile applications is being developed as the IEEE 802.20 standard, ${ }^{\text {lxxix }}$ while a chip set recently announced for laptops will provide data connections globally without locking users to a particular telecommunications carrier. ${ }^{\operatorname{lxx} x}$

\section{Conclusions}

The eventual impact of IEEE Std 802.16 is expected to be broad and global, benefiting private industry participants in terms of new markets and decreased costs and end-users in terms of greater functionality at comparable price points to existing broadband technology. The WiMAX standard has spawned a new ecosystem of manufacturers and service providers investing in the technology, with more than 700 
companies having been represented to the IEEE 802.16 Working Group, and forming large industry groups including the WiMAX Forum and the WiMAX Spectrum Owners Alliance. The creation and existence of a WiMAX ecosystem were noted as being important for innovation by the majority of our survey respondents.

The standard will clearly make an impact on the digital divide both in the developing world, where there is little or no copper or fiber infrastructure, as well as rural areas of the developed world. The standard is having significant market impact in the US municipal wireless sector and in the mobile data and voice market. Internationally, the standard is a strong competitor and has gained ITU acceptance into the family of mobile standards as a sixth IMT-2000 radio interface. The business model, which will allow WiMAX to be present in many types of consumer devices in addition to laptops and cellphones, and its time-to-market lead are other advantages which WiMAX has over other competing wireless broadband technologies. In the next three- to-five years, tens of millions are expected to be users of this technology around the world and the technology should become broadly diffused.

For its part, NIST served as a catalyst in helping to get the standards programs launched following the model used for data communications. It provided the staff person to perform the duty of chair of the 802.16 Working Group and provided all of the support work involved with this function. This leadership role provided the chair the ability to act as a neutral arbitrator on a committee made up almost entirely of industry representatives and was seen as a key benefit of NIST's involvement. The Chair was elected four times while a staff member at NIST. The net result of NIST's effort is that it may have accelerated adoption of the WiMAX standard and resulting benefits of the standard by as much as 1.5 years. It is not easy to separate the role that NIST played v. the individual effort and commitment of the Chair, but the survey of industry participants indicated that the overall NIST role was both positively received and beneficial to the development effort.

The estimated cost to develop the standard, \$206 million dollars, needs to be assessed against quantified benefits in a future economic impact study. Based on qualitative information and forecasts contained in this report, this should yield a positive return on investment. It remains for a further more detailed study to determine the actual economic impact of the IEEE 802.16 standard. It can be argued that NIST delivered value to the standard development process disproportionate to its approximately one percent share of the overall development cost.

Challenges remain for WiMAX to reach its potential. WiMAX has yet to be demonstrated as a large, highly-utilized fixed or mobile system where service quality can be assessed over time, distance, and number/type of end user. There may be significant technical issues to be addressed, such as mobile device power requirements and battery performance. Business models must evolve and return-on-investment performance must justify sunk costs. 
This study is a building block in the effort to develop a methodology for conducting evaluations of documentary standards efforts. The ultimate goal is to develop a standard methodology that quantifies benefits and costs to arrive at a measure of net economic benefit. Based on the background and data compiled in this study, a complete economic analysis effort can be undertaken once WiMAX has been fully commercialized with measurable benefits in the next 3-5 years. 


\section{Appendix 1. IEEE 802.16 Published Standards and Drafts (as of 12/2007)}

IEEE Standard for Local and Metropolitan Area Networks - Part 16: Air Interface for Fixed Broadband Wireless Access Systems

\section{Active Standards}

- $\quad$ IEEE Std 802.16-2004, as amended by

o $\quad$ IEEE Std 802.16g-2007 (amendment to IEEE 802.16) Management Plane Procedures and Services

o IEEE Std 802.16f-2005 (amendment to IEEE 802.16) Management Information Base

o IEEE Std 802.16e-2005 (amendment to IEEE 802.16) Physical and Medium Access Control Layers for Combined Fixed and Mobile Operation in Licensed Bands

o IEEE Std 802.16-2004/Cor1-2005 (corridendum to IEEE 802.16, published along with IEEE 802.16e-2005)

- IEEE Std 802.16k-2007 Standard for Local and Metropolitan Area Networks: Media Access Control (MAC) Bridges - Bridging of 802.16

\section{Drafts Under Development}

- IEEE Draft P802.16h Improved Coexistence Mechanisms for License-Exempt Operation

- IEEE Draft P802.16i Management Plane Procedures and Services

- IEEE Draft P802.16j Multihop Relay Specification

- IEEE Draft P802.16m Advanced Air Interface

- IEEE Draft P802.16Rev2 This work will result in the second revision of IEEE Std 802.16, following IEEE Std 802.16-2001 and IEEE Std 802.16-2004. It will consolidate IEEE Standards 802.16-2004, 802.16e-2005, 802.16-2004/Cor1-2005, 802.16f-2005, and 802.16g-2007. 


\section{Appendix 2. Case study: Grand Rapids Michigan ${ }^{\mid x \times x i i}$}

On December 1, 2006, the Grand Rapids City Council voted to award a citywide wireless contract to Clearwire LLC. The build-out of the system is taking place in 2007. This network is unique for a number of reasons: 1)It is the first 802.16e (not preWiMAX) municipal wireless network to be implemented in the United States. 2) The network will contain WiMAX/Wi-Fi hybrid hotspots. The network will cover 45 square miles and a population of approximately 200,000, with 18 to 20 towers throughout the city. Coverage will extend throughout the city limits. In addition to outdoor coverage, at least $90 \%$ of interior rooms in residential, municipal and commercial building will be covered, including areas above the second floor. The service will be suitable for VoIP telephone service. Public safety vehicles will be able to access the network, including real-time video streaming and photo transfer at speeds up to 70 miles per hour. Clearwire will sell the service at retail rates and will also provide wholesale Internet access to other service providers. Clearwire has agreed to provide discounted service to qualifying low income residents for up to five percent of total household count in Grand Rapids. Cost of discounted service will be $\$ 9.95$ per month for Internet access with downlink speed up to $512 \mathrm{kbit} / \mathrm{s}$ and uplink speed to $256 \mathrm{kbit} / \mathrm{s}$.

The city has partnered with a local non-profit organization, the Community Media Center (CMC), for low income account processing. Free public presentations and signup sessions will be available in various locations throughout the city. The city and CMC are working together to draft appropriate guidelines and procedures. The goal is to keep the process simple while ensuring that all citizens receiving the discounted service are qualified, low income residents. Free Wi-Fi hot spots will also be provided for visitors and occasional users.

The decision to use WiMAX for the Grand Rapids municipal network offers many benefits and innovative new uses for municipal employees and citizens of Grand Rapids. The following is a list of how Grand Rapids intends to utilize the network from a capacity and application perspective:

\section{Primary Municipal Applications}

- The city expects to use the network first as a public safety network for police and fire and then as a method to assist city workers in making them more productive in their work. The applications that are anticipated to be used by Public Safety are:

o Intranet access to local, state and federal databases

o Internet access to certain databases

o Field reporting

o Email connectivity

o Digital photos pushed to all users

o Limited video surveillance

- For all other anticipated city employee segments, it is anticipated that records updating and work order management will be the primary use of the system. We also 
anticipate that these workers will require Internet connectivity along with email access.

\section{Potential Applications for Education}

- Student access to current school information, homework assignments, and help via a school Web site and remote teaching

- Improved communication between school administration, teachers, parents, and students with use of email

- College and university access to campus network for off-campus students and distant learning

- Video surveillance for campus police use

\section{$\underline{\text { Potential Economic Development Applications }}$}

- Wireless internet service provider (ISP) partnerships

- "Smart zone" growth opportunities

- Low-cost, high-speed Internet access for homes and small businesses

- Create an inviting atmosphere for conventioneers, tourists, and visitors

- Attract new businesses, entrepreneurs and young professionals creating a "cool" city

\section{Potential Heath Care Applications}

- Remote monitoring of patients with chronic illnesses

- First responder access to vital patient information and medical assistance

- Broadband access to patient data while patients are in route to a hospital 


\section{End Notes}

${ }^{i}$ Pareek, D. “The business of WiMAX”, John Wiley \& Sons, LTD, West Sussex, England, 2006

ii Selected Impacts of Documentary Standards Supported by NIST (NISTIR 7398), National Institute of Standards \& Technology, March 2007

${ }_{\text {iii }}$ Methods for Assessing the Economic Impacts of Government R\&D (Planning Report 03-1), NIST, September 2003

${ }^{\text {iv }}$ DTI (2005), DIN (2000), Blind (2004) and others

${ }^{v}$ Hesser, et. al. "Standardization in Companies and Markets" September 2006, p. 79

vi Toth, et. al., "The Economics of Standardization”, 1984, p.17

vii Hesser, Ibid., p. 133

viii DIN 2000, p.4

${ }^{\text {ix }}$ DIN 2000, p. 82-83

xR. B.Marks, "Broadband Wireless Access for the First Mile,” National Science Foundation "Last Mile Panel,” April 8, 1999

$<$ http://nwest.nist.gov/first_mile.pdf>.

xiR. B.Marks, “Standards Make Wireless Work,” Applied Microwave \& Wireless Magazine, pp. 101-102, February 1999

<http://nwest.nist.gov/editorial_amw.html>.

xii R. B.Marks, “Cooperative International Wireless Standardization,” European Institute Roundtable: Spanning the Spectrum of

Communications Policy, May 6, 1999 <http://www.standardsresearch.org/standards-discuss/0006.html>.

xiii R. B.Marks, “IEEE Standardization for the Wireless Engineer,” IEEE Microwave Magazine, pp. 16-26, June 2001

<http://WirelessMAN.org/docs/01/80216c-01_09.pdf>.

xivR. B.Marks, Ian C. Gifford, and Bob O’Hara, “Standards from IEEE 802 Unleash the Wireless Internet,” IEEE Microwave

Magazine, pp. 46-46, June 2001 <http://WirelessMAN.org/docs/01/80216c-01_10.pdf>.

${ }^{\mathrm{xv}}$ R. B.Marks, “Advances in Wireless Networking Standards,” Pacific Telecommunication Review, pp. 30-

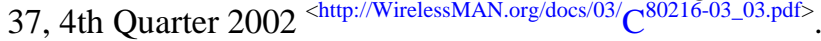
xvi <http://WirelessMAN.org>

xvii IEEE Standard 802.16-2001 (“IEEE Standard for Local and metropolitan area networks_-Part 16: Air Interface for Fixed Broadband Wireless Access Systems") <http://ieee802.org/16/published.html>.

xviii Carl Eklund, R. B.Marks, Kenneth L. Stanwood, and Stanley Wang, "IEEE Standard 802.16: A

Technical Overview of the WirelessMAN Air Interface for Broadband Wireless Access," IEEE

Communications Magazine , pp. 98-107, June 2002 <http://ieee802.org/16/docs/02/C80216-02_05.pdf>.

${ }^{x i x}$ R. B.Marks, "IEEE Standard 802.16 for Global Broadband Wireless Access," ITU Telecom World 2003

Geneva, October 12-18, 2003 <http://ieee802.org/16/docs/03/C80216-03_14.pdf>.

${ }^{x x}$ Data from NIST, EEEL, Electromagnetics Division, Boulder Colorado

${ }^{x x i}$ Source: IEEE 802.16 Working Group website

xxii This figure represents instances where the country of origin was identified. In 99 cases it was not.

xxiii Figure estimated based on the number of participants times $\$ 27,200$ which is the average loaded cost

for each Working Group participant as calculated by data from the survey respondents and 802.16 Working Group statistics

xxiv Maravedis, "WiMAX and Broadband Wireless Worldwide Market Analysis and Trends 2006-2012", p.138

${ }^{\mathrm{xxv}}$ WiMAX is a technology segment within the overall broadband wireless access market.

xxvi Ibid.

xxvii Infonetics Research, press release, March 15, 2007

xxviii Maravedis, WiMAX Counts Facts \& Figures, Webinar July 10, 2007

xxix The number of individual WiMAX implementations

${ }^{x x x}$ Source: WiMAX Forum September 2007

xxxi WiMAX Trends 1/25/2007

xxxii Maravedis, WiMAX Counts Facts \& Figures, Webinar July 10, 2007

xxxiii Presentation by FCC Commissioner Jonathan Adelstein "National Priorities for Broadband Wireless"

at WCA 2007, June 13, 2007

${ }^{\text {xxxiv }}$ Incumbent local exchange carriers which include "Baby Bells" from the 1984 break-up of AT\&T 
xxxv Presentation at WCA 2007, "Rural Broadband”, June 13, 2007

xxxvi NSR, Technological Leapfrogging via WiMAX, p. 7, February 2007

xxxvii WiMAX outlook in the US market: implications for service providers”, Diamond Management and Technology Consultants, 2007

xxxviii Maravedis, "WiMAX and Broadband Wireless Worldwide Market Analysis and Trends 2006-2012", Exhibit 189

${ }^{x x x i x}$ NSR, Technological Leapfrogging via WiMAX, p. 8, February 2007

${ }^{\mathrm{xl}}$ Maravedis, "WiMAX and Broadband Wireless Worldwide Market Analysis and Trends 2006-2012”, Exhibit 187

${ }^{x l i}$ One exception to this was in a study by Arthur D. Little which estimates that WiMAX will capture perhaps 10 percent of the mobile broadband wireless subscribers by 2011-2012

xlii Maravedis 9/2006, Infonetics Research 3/2007 (est.), NSR 2/2007

xliii Our approach is modeled after that used by Robert Chapman in his study of benefits and costs associated with construction system, "Benefits and costs of research: a case study of construction systems integration and automation technologies in commercial buildings", NIST Building and Fire Research Library, December, 2001

xliv Patrick, D. et al. “Commonwealth of Massachusetts FY2008-2012 five-year capital investment plan”, August, 2007

xlv One estimate of the cost efficiencies due to cellular network architecture states that WI-FIWI-FI Mesh Captal Expense (CAPEX) of $\$ 100,000$ - $\$ 150,000$ per square mile versus a WiMAX CAPEX of $\$ 14,000$ \$24,000 per square mile (Edwards K. "WiMAX to the Max" Excelsio Communications, 2007)

xlvi Statetechmag.com, July/August 2007, p. 39

xlvii Voxilla 'Broadband Gets Personal’ 4/19/07

xlviii Motorola press release, June 20, 2007 “American Consumers to Use WiMAX Wireless Broadband for On-The-Go Email, Web Surfing, Mobile TV, Music Survey Shows

${ }^{x}$ lix WiMax Counts Quarterly Newsletter June 2007

${ }^{1}$ Reuters 4/8/2007

li Owens D., “Expanding Rural Access: Working Papers”, p.9 February 26, 2007

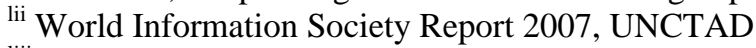

liii Standardisation in Companies and Markets, Hesser, et al. September, 2006, p. 76

liv Vietnam LMI: Associated Working Papers, December 20, 2006

${ }^{\text {lv }}$ Business Week, "WiMAX Helping Asia's Farmers", September 4, 2007

lvi Media Release 80/07, 18 June 2007, by Senator the Hon Helen Coonan, Minister for Communications, Information Technology and the Arts, "Australia Connected: Fast affordable broadband for all Australians

lvii Horrigan, John, "Why it Will be Hard to Close the Broadband Divide", Per Internet \& American Life Project, 8/1/2007

lviii Flamm, K. "Diagnosing the disconnected: where and why is broadband access unavailable in the U.S.?”, working paper revised September 2006, presented at the Telecommunications Policy Research Conference, Fairfax, VA, September 30, 2006

lix Presentation at WCA 2007, "GovMax: Government Initiatives and Applications, Kenneth Kuchno, USDA, June 13, 2007

${ }^{\text {lx }}$ Flamm, ibid.

${ }^{\text {lxi }}$ Muniwireless.com, 2006

Ixii Sekino, H. et al. "WiMAX outlook in the US market: implications for service providers", Diamond Management and Technology Consultants, 2007

lxiii State of the Market Report, Muniwireless.com, October 2006

${ }^{\text {lxiv }}$ www.telecomweb.com, Earthlink crumbles as Second City ditches Wi-F-, August 30, 2007

${ }^{\mathrm{lxv}}$ www.redherring.com, The business of technology; Muni Wi-FiWi-Fi collapse a boon for WiMAX, September 9, 2007.

lxvi www.informationweek.com, A wireless dream? Pace Micro shows WiMAX combo to the home, September 7, 2007.

lxvii http://pr-gb.com, Is Sprint the champion of mobil WiMAX growth? August 20, 2007

lxviii WiMAX Day, July 7, 2007

lxix WiMAX Day, July 16, 2007 
Ixx D. Foray, Standardview Vol 6, No. 2, p.83 June 1998

${ }^{\text {lxxi }}$ Bhatia p.2 Stimulating v. Stifling: Standardization's Role in Innovation, Standards Edge Conference, Washington, DC 3/22/07

Ixxii DTI Economics Paper No. 12, p. 37, June 2005

lxxiii Blind, ISO Focus, Vol 4, No. 6, June 2007, pp. 43-44

Ixxiv NSR, Technological Leapfrogging via WiMAX, p.2, February 2007

${ }^{\text {lxxv }}$ www.channelnewsasia.com. "Singapore's seaport to be world's first WiMAX enabled by 2008", September 26, 2008

lxxvi http://www.rwonline.com, "Radio listening will drop once Wi-Fi, WiMAX entrenched in car", September 14, 2007

Ixxvii Recent reports have the number of WiBro subscribers surpassing 100,000 17 months after launch (Koreatimes, December 2, 2007)

lxxviii Wi-FiWi-Fi Planet, "NextWave mixes technologies", www.wi-

fiplanet.com/news/article.php/3684771, June 21, 2007

Ixxix Techworld, “WiMax rival lives again at IEEE”, www.techworld.com, July 20, 2007

${ }^{\text {lxxx }}$ Computerworld Mobile \& Wireless, "New Gobi chip set: A Xohm killer?, October 25, 2007

Ixxxi The IEEE 802.16 Working Group on Broadband Wireless Access Standards (website)

lxxxii Information compiled from Grand Rapids website (http://www.grand-rapids.mi.us/) and other information provided by employees 